This is a self-archived - parallel published version of this article in the publication archive of the University of Vaasa. It might differ from the original.

\title{
Natural Gas-Diesel Reactivity Controlled Compression Ignition with Negative Valve Overlap and In-Cylinder Fuel Reforming
}

Author(s): Mikulski, Maciej; Balakrishnan, Praveen Ramanujam; Hunicz, Jacek

Title: Natural Gas-Diesel Reactivity Controlled Compression Ignition with Negative Valve Overlap and In-Cylinder Fuel Reforming

Year: $\quad 2019$

Version: Accepted manuscript

Copyright Elsevier, Creative Creative Commons Attribution NonCommercial No Derivatives License

Please cite the original version:

Mikulski, M., Balakrishnan, P.R., Hunicz, J., (2019). Natural Gas-Diesel Reactivity Controlled Compression Ignition with Negative Valve Overlap and In-Cylinder Fuel Reforming. Applied Energy 254:15. https://doi.org/10.1016/j.apenergy.2019.113638 


\title{
Natural Gas-Diesel Reactivity Controlled Compression Ignition with Negative Valve Overlap and In-Cylinder Fuel Reforming
}

\author{
Maciej MIKULSKI ${ }^{a, *}$, Praveen Ramanujam BALAKRISHNAN ${ }^{b}$, Jacek HUNICZ ${ }^{c}$ \\ ${ }^{a}$ School of Technology and Innovation, Energy Technology, University of Vaasa, Wolffintie 34, FI-65200 Vaasa, Finland \\ ${ }^{b}$ Department of Mechanical Engineering, Eindhoven University of Technology, 5600 MB Eindhoven, The Netherlands \\ ${ }^{c}$ Faculty of Mechanical Engineering, Lublin University of Technology, Nadbystrzycka 36, 20-618 Lublin, Poland \\ *Corresponding author; E-mail:maciej.mikulski@uwasa.fi
}

\begin{abstract}
Dual-fuel reactivity controlled compression ignition combustion offers potentially superior overall efficiency and ultra-low nitrogen oxides and soot emissions. Using natural gas as the low reactivity fuel also provides high knock-resistance and carbon dioxide emission reduction. However, the concept suffers from relatively low combustion efficiency at low engine loads, causing unacceptable methane slip. This study tackles this issue, applying numerical simulations to investigate the application of negative valve overlap to improve combustion efficiency of reactivity controlled compression ignition at low engine loads. The objective is modification of in-cylinder thermal and chemical state before combustion, by varying timing and amount of fuel injected directly into the recompressed hot exhaust gases. The study uses TNO's multi-zone, chemical kinetics-based combustion model with variable valve actuation functionality. The simulation is based on two experimentally validated cases: an uncooled exhaust gas recirculation strategy and a lean burn concept. In both eases, negative valve overlap elevates in-cylinder temperature and cuts methane emissions by $15 \%$, without combustion optimization. Crucially, it enables peak exhaust recompression temperatures above $850 \mathrm{~K}$, sufficient for diesel reforming/oxidation. The lean RCCI strategy takes greater advantage of fuel reforming than the exhaust gas recirculation case. Optimum conditions give almost $99 \%$ combustion efficiency and ultra-low methane emissions. Net indicated efficiency is 40.5\%(@15\%load),despite negative valve overlap's substantial pumping losses. Low-load net efficiency is 5.5 percentage points above the lean strategy baseline and 3 pp. better than the exhaust gas recirculation baseline. This strategy is considered applicable on state-of-the-art dual-fuel gas engines without hardware changes.
\end{abstract}

Keywords: RCCI, Natural Gas, Variable Valve Actuation, Negative Valve Overlap, Fuel Reforming, Residuals.

\section{Nomenclature}

\begin{tabular}{|c|c|}
\hline$\dot{\boldsymbol{m}}$ & mass flow rate \\
\hline $\boldsymbol{\eta}$ & $\begin{array}{l}\text { efficiency: I - indicated (gross or net), Comb - } \\
\text { combustion }\end{array}$ \\
\hline$\lambda$ & air-fuel equivalence ratio \\
\hline $\begin{array}{l}\text { aTDC / } \\
\text { bTDC }\end{array}$ & after / before top dead center \\
\hline $\mathbf{B R}$ & blend rate \\
\hline $\mathbf{C A}$ & crank angle \\
\hline CAXX & crank angle at $\mathrm{XX} \%$ heat released [CA] \\
\hline $\mathrm{CH}_{4}$ & methane \\
\hline CHR & cumulative heat release \\
\hline CI & compression ignition \\
\hline $\mathbf{C O}$ & carbon monoxide \\
\hline $\mathrm{CO}_{2}$ & carbon dioxide \\
\hline CR & compression ratio \\
\hline EGR & exhaust gas recirculation \\
\hline EVO & exhaust valve opening \\
\hline HCCI & homogenous charge compression ignition \\
\hline HRR & heat release rate \\
\hline IMEP & indicated mean effective pressure \\
\hline IOCV & independently operated closing valve \\
\hline IVC & intake valve closing \\
\hline IVO & intake valve opening \\
\hline LTC & low temperature combustion \\
\hline MSR & $\begin{array}{l}\text { mass split ratio of diesel between NVO and } \\
\text { main injection }\end{array}$ \\
\hline MOP & maximum operating point \\
\hline NG & natural gas \\
\hline $\mathbf{N O}_{\mathbf{x}}$ & nitrogen oxides \\
\hline
\end{tabular}

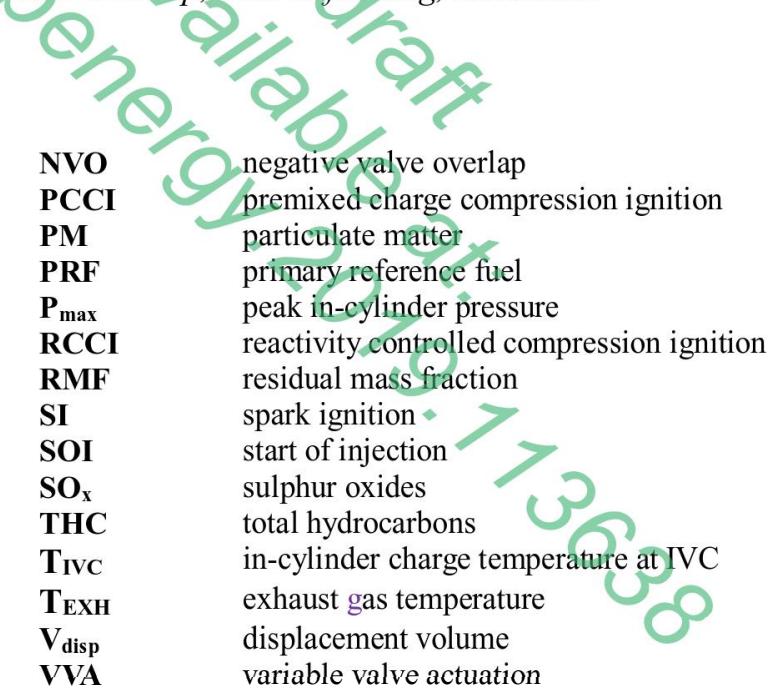

\section{Introduction}

Reactivity Controlled Compression Ignition (RCCI) technology is one of the contemporary Low Temperature Combustion (LTC) solutions for heavy-duty engines. It combines two fuels with different reactivity. The lowreactivity fuel is usually homogenously mixed within the combustion chamber, while a small portion of the highreactivity fuel is directly injected early during the compression stroke. The objective is stratification across the cylinder volume to achieve a controllable combustion process 
with low local temperatures, hardly triggering the $\mathrm{NO}_{\mathrm{X}}$ production mechanism.

RCCI has been extensively tested during the last 10 years with a variety of fuel combinations and different engine platforms. For an extensive review of the results achieved, the reader is referred to a recent work by Reitz and Duraisamy [1]. Natural gas (NG) is one of the feasible low-reactivity fuels for RCCI, combining the benefits of low carbon content and high knock resistance [2].

NG-diesel RCCI was experimentally demonstrated on heavy-duty engines by, among others, Jia et al. [3], Dahodwala et al. [4] and Doosje et al. [5]. The authors consequently reported the possibility to reach $\mathrm{NO}_{X}$ emissions below Euro VI levels without using aftertreatment. Jia et al. [3], in particular, demonstrated gross indicated thermal efficiency of $52 \%$, noticeably better than baseline diesel combustion and thereby progressing towards the goal of $50 \%$ brake thermal efficiency (BTE) in heavy-duty truck engines [6].

While the difference in fuel reactivity provides a way of controlling combustion, it also introduces additional difficulties due to the complex chemistries of the reacting species. In addition, the high-load operating range is constrained as a direct result of high in-cylinder pressures and steep pressure rise rates arising from rapid RCCI combustion [7]. Although the reduction of the engine's compression ratio (CR) or the temperature of re-circulated exhaust has been proven to be able to counter this challenge [8], it also tends to negatively impact combustion efficiency [9].

Substantial methane $\left(\mathrm{CH}_{4}\right)$ slip at low loads is another challenge. Combustion propagation is relatively weak at low loads because there is insufficient mixing since the combustion chain initiated in diesel-rich areas (primarily near the cylinder wall) breaks before reaching the lean region near the center of the cylinder. Consequently, there is incomplete combustion in the gaseous region at the center of the cylinder, leading to excessive methane slip. The use of higher compression ratios $[3,10]$ could potentially overcome this hurdle, similarly to the use of elevated charge temperature at intake valve closure [11,12] or decreasing the gas-diesel blend ratio (BR) [13]. But a higher CR is already detrimental to high-load operation, so other methane slip prevention measures, such as NG stratification $[9,14]$ or $\mathrm{CH}_{4}$ catalytic reduction [15] need to be considered. NG stratification requires the use of dedicated high-pressure NG injection systems. Catalytic reduction is hampered by the fact that lowtemperature RCCI combustion can render methane oxidation catalysts ineffective because their light- off temperature is difficult to reach without external heating.

From the above summary it becomes evident that conventional engine-control strategies do not enable efficient RCCI operation across the full engine map. Introducing variable valve actuation (VVA) is considered as a potential enabler for RCCI. Multiple strategies are possible with VVA, modifying both valve timing and lift [16]. VVA has also been successfully applied to enable LTC with either homogeneous charge compression ignition (HCCI) or partially premixed compression ignition (PCCI). The effects of VVA on HCCI combustion are broadly discussed in the work of Hunicz and Kordos [17].
With regard to RCCI, most VVA research has focused on extending high-load operation, making use of different intake valve actuation strategies. Molina et al. [18] and Benajes et al. [19] applied Miller cycle to control effective compression ratio in a gasoline-diesel RCCI engine. Reduction of thermodynamic compression ratio from ca. 14 to 11 by early intake valve closing with suitable low- and high-reactivity fuels proportions gave soot and $\mathrm{NO}_{\mathrm{X}}$ emissions below Euro VI limits. This strategy was further validated by García-Valladolid [20] on a medium-speed marine engine in the context of maritime emission regulations. Furthermore, high emissions-sensitivity to the timing of diesel pilot fuel injection was demonstrated. The recent study by Mikulski et al. [21] includes a summary of such relevant literature, identifying knowledge gaps. The authors used variable intake valve measures to successfully demonstrate NG-diesel RCCI high-load envelope extension. Late intake valve opening (IVO) strategy was identified as one of the measures to address this in [21] and for the same NG-diesel RCCI platform, the strategy was tested for a 3 bar IMEP low-load point. This necessitated adjustment of the fuel blend ratio (BR) to maintain constant combustion phasing for the late IVO sweep. For the chosen engine configuration, it was found that the thermal effects of this strategy, due to the increase in internal exhaust gas re-circulation (EGR) at late IVO timings, had a greater role to play towards combustion efficiency improvement than the mixing energy increase also resulting from late IVO. Methane slip was reduced by about $25 \%$ along with THC emissions, while still maintaining ultralow NOX emissions. Xu et al. [22] performed multiparameter optimization, where control parameters included VVA, BR, diesel stratification and EGR. The studies showed that a late IVC strategy does not diminish combustion efficiency but substantially reduces $\mathrm{NO}_{\mathrm{X}}$ emissions at low loads. However, in the light of Euro VI limitations the authors pointed out the necessity of using at least one exhaust aftertreatment device to maintain low tailpipe emissions at higher loads

Additionally, exhaust-valve double lift (2EVO) was tested as a low-load thermal management measure in [21]. Almost 98\% reduction in engine-out $\mathrm{CH}_{4}$ emissions and about $100 \mathrm{~K}$ increase in exhaust temperature $\left(\mathrm{T}_{\text {exh }}\right)$ were observed, paving the way for highly efficient low-load aftertreatment performance. The early exhaust valve opening (EVO) simulation study by Bharat et al. [23] on a multicylinder gasoline-diesel RCCI engine demonstrated better aftertreatment performance but power output was penalized because the expansion stroke work was terminated by the early opening of the exhaust valve.

Negative valve overlap (NVO) is a promising VVA measure to improve low-load efficiency. It has been successfully tested on HCCI engines fueled with high octanenumber fuels $[24,25]$. NVO traps the exhaust gases within the cylinder and these hot gases undergo re-compression with piston motion. Consequently, auto-ignition of gasoline-like fuels can be achieved at relatively low compression ratios, typical of a spark-ignition engine. It should be noted, however, that application of NVO is restricted to low engine loads, because internally re-circulated exhaust gases limit fresh air aspiration. The first research results demonstrating the NVO technique on compression ignition operation were 
provided by Lavy et al. [26] and Kontarakis et al. [27]. Koopmans et al. [28] pointed out that exhaust gas recompression during the NVO period generates additional thermal losses, reducing overall engine efficiency. In contrast, a recent work by Rodriguez and Cheng [29] demonstrated that running a gasoline engine with optimized $\mathrm{NVO}$ configuration can reduce fuel consumption at part loads by $7 \%$ in comparison to positive valve overlap operation. The benefits and disadvantages of simple NVO operation are also illustrated clearly in the work by Borgqvist et al. [30].

NVO can also be used to achieve on-board fuel reforming. Hot recompressed exhaust gases provide the necessary thermal conditions to initiate fuel chemical reformation reactions. Urushihara et al. [31] demonstrated that when gasoline fuel was injected directly into the cylinder during the NVO period, the fuel species underwent chemical reformation and the reformed fuel mixture made it possible to extend the HCCI lean-operation limit. They also noted that split fuel injection and injeeting only a portion of fuel during the NVO period improves thermal efficiency of the cycle. Recently, Hunicz [25] also observed similar trends on an HCCI engine running with optimized fuel-injection split ratios. The impact of chemical effects from fuel reforming is clearly illustrated by Fitzgerald and Steeper [32] in their computational analysis of chemical reactions during NVO. The observation was that when fuel was injected towards the end of the exhaust recompression phase, advanced autoignition occurred, despite lower IVC temperatures $\left(T_{T Y C}\right)$. Furthermore, the study by Borgqvist et al. [33] on a gasoline partially premixed combustion (PPC) engine show that fuel injection during NVO provided additional combustion stability improvements that other rebreathing strategies cannot offer. This indicates that fuel reforming indeed produced products promoting combustion. Some studies also experimentally quantified species production during the NVO period [34, 35]. Studies by Yu et al. [36] and Puranam and Steeper [37] provide information about the influence of certain species towards autoignition. Acetylene $\left(\mathrm{C}_{2} \mathrm{H}_{2}\right)$, ethylene, formaldehyde and methanol were identified as autoignition promoters. Recently, Ekoto et al. [38] have determined gasoline autoignition shifts resulting from mixture reactivity that was controlled via the fuel quantity and injection timing during NVO.

Aroonsrisopoin et al. [39] and Waldman et al. [40] analyzed the extent of thermal and chemical effects of gasoline direct injection during NVO. Combined experimental and simulation research determined that both fuel reforming and heat release took place during the NVO phase, but the influence of either effect was a function of the fuel distribution between the NVO and main compression phase. The authors deduced that thermal effects assume less significance when the NVO injection quantity was comparatively large. In a more recent study, Hunicz and Mikulski [41] illustrated that direct fuel injection into retained residuals during $\mathrm{NVO}$ enabled control of the start of combustion in an HCCI engine in the range of 5 to $10 \mathrm{crank}$ angle degrees, based on the global mixture strength. The injection timing during the NVO period was used as a parameter to control the balance between evaporative cooling and exothermic reactions of the fuel species.
On the RCCI side, information about NVO direct injection is scarce. Kuzuoka et al. [42] (Honda R\&D) used diesel direct injection during NVO of a gasoline-diesel RCCI engine and observed that the oxidation reaction of diesel fuel was hindered by the products from partial NVO oxidation of diesel. This reduced combustion activity was used to control combustion and displayed improved thermal efficiency at low loads. The ignition delay was altered by varying the ratio of diesel fuel injected during NVO.

In addition to NVO direct injection, recent studies have also demonstrated other (external) fuel reforming techniques to improve LTC performance. Neshat et al. [43] made a numerical study of the effects of external reforming of primary reference fuels combustion in an HCCI engine. The addition of reformer gas delayed autoignition for fuel with high content of $n$-heptane. It reduced $\mathrm{NO}_{\mathrm{X}}$ emissions while increasing $\mathrm{CO}$ and hydrocarbons emissions. Notably, Hwang et al. [44] showed that single-fuel RCCI operation is attainable with a thermally integrated EGR reactor (external to engine cylinders). It was found that RCCI operation is possible if the reformate generated using the reactor was inferior in reactivity compared to diesel. At low equivalence ratio, higher hydrocarbon emissions and significant ignition delay were observed. The BTE was also lower compared to conventional diesel combustion.

Recent studies by Lin et al. [45] clearly demonstrated the potential of partial external fuel reforming to achieye high efficiency in RCCI operation for a wide local equivalence ratio from 0.4 to 7.1 , with a relative stable global equivalence ratio. Apart from RCCI, fuel reforming using a dedicated cylinder in the engine has been tested for diesel combustion by Asai et al. [46], using the cylinder eompression heat to partially oxidize a rich fuel mixture. Fuel reforming was found to occur at temperatures around 1200$1400 \mathrm{~K}$. The reformed mixture contained $\mathrm{H}_{2}, \mathrm{CO}, \mathrm{CH}_{4}$ diluted with $\mathrm{CO}_{2}$ and $\mathrm{H}_{2} \mathrm{O}$, and was fed as a lean homogenous mixture to the other firing cylinders. It is worthwhile to observe that NVO direct injection can offer similar fuel reforming effects without sacrificing a dedicated cylinder or requiring an external reactor.

Based on the above remarks, Fig. 1 illustrates an overview of the current research status of VVA applications in dual-fuel RCCI engines. The knowledge gaps thus identified are discussed in further detail in Section 2.

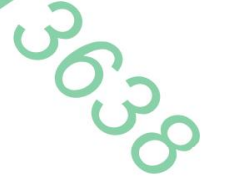




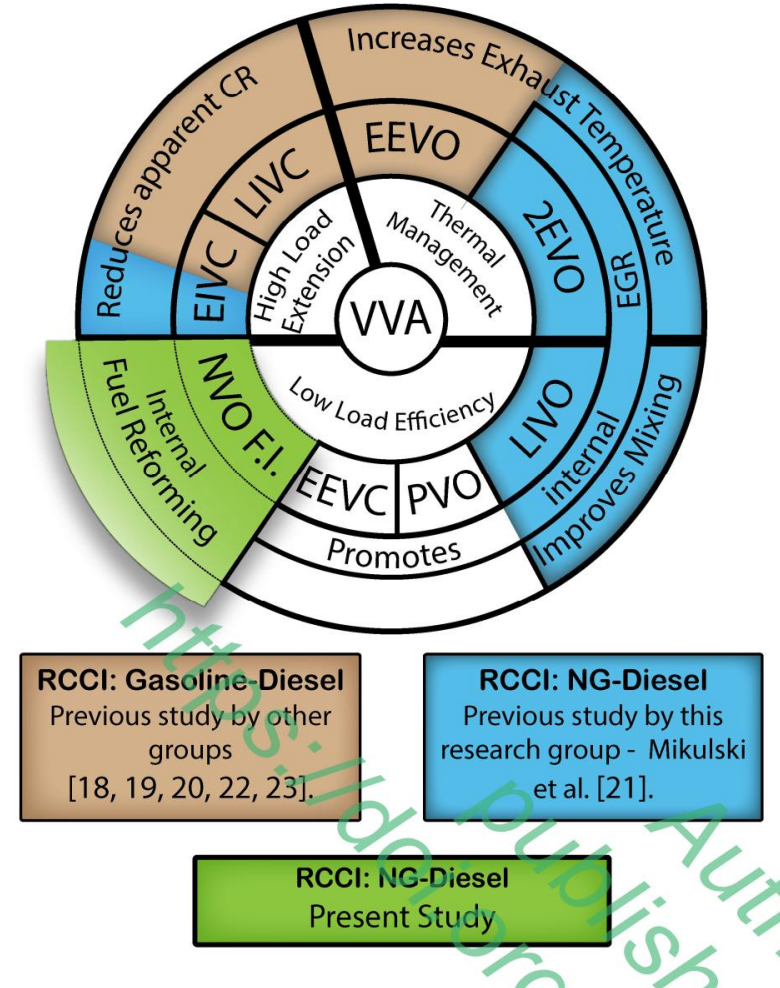

Figure 1. Review of VVA strategies for lodd range extension, efficiency improvement and thermal management. The focus is on RCCI NG-diesel concept. The areas where the knowledge gap is partially filled by gasoline-dieset RCCI research are colored in brown.

\section{Motivation and research objectives}

NG-diesel RCCI combustion is one of the considered solutions for future heavy-duty road and marine transport. This is due to its capability of attaining diesel-like load range and ultra-low emissions, combined with substantial $\mathrm{CO}_{2}$ impact reduction through high efficiency and low carboncontent fuel. However, incomplete combustion at low engine loads causes excessive methane slip: this is one of the pending issues inhibiting widespread application of this concept. To achieve reasonable low-load performance RCCI is usually operated on the upper limit of attainable intake temperatures and lower limit in BRs [5]. Further elevating IVC temperature and improving mixture reactivity in the lean regions of the cylinder might support more complete combustion.

The literature survey of low-temperature combustion concepts in the introduction section indicates that operating the engine in the NVO mode can achieve this desired boost in IVC temperatures [31], while, depending on the NVO conditions, additional fuel injection can provide extra control in terms of mixture reactivity and reactivity stratification. The actual effects are highly dependent on properties of the fuel subjected to reformation, mixture strength, reforming temperature residence time and finally, the combustion concept. Most research available focuses on altering the mixture reactivity for single fuel PCCI or HCCI [41] concepts. For dual-fuel RCCI, only the researchers from Honda [42] have explored the potential of on-board fuelreforming for their light-duty, gasoline-diesel development platform, confirming the feasibility to improve low-load performance. Low-load improvement can bring much higher overall benefits for NG-diesel RCCI, but here the NVO direct injection strategy has not been researched at all. So here, in a nutshell, is the justification and motivation for this study: there is a serious knowledge gap about the application of a strategy which could yield worthwhile performance and emission benefits.

The authors' premise is that that low-load RCCI operation can be improved with a combination of NVO and direct diesel injection into recompressed residuals. Validating this hypothesis is the primary goal of the present research.

Two fundamentally different operational modes, each already proven successful for achieving efficient low-load RCCI, have been chosen as the study's baselines. One is a heavy, uncooled EGR mode; the other is a lean-burn nonEGR mode. With heavy, uncooled EGR, the NVO strategy should help elevate exhaust temperature for more efficient thermal management (catalyst light-off temperature) while the increase in trapped hot residuals, together with homogenizing the diesel mixture (NVO direct injection), is expected to further improve combustion efficiency. In the lean-burn non-EGR mode, due to high oxygen content in exhaust gasses, chemical fuel reforming effects during NVO are suspected to play a dominant role in improving mixture reactivity at the main combustion event, thus supporting complete combustion.

Numerical simulations are performed using TNO's inhouse multizone, chemical kinetics-based combustion model with variable valve actuation functionality. The study included the following steps towards fulfillment of the main goal:

(i) The model is carefully validated against the RCCI experimental data on the EGR and non-EGR mode.

(ii) The valve profiles are further modulated in the model to achieve negative valve overlap and ultimately, exhaust gas recompression during this phase.

(iii) The timing and amount of diesel fuel injected directly into the recompressed hot exhaust gasses, are both varied. This is done to identify and understand the potential effects of fuel reforming on the in-cylinder thermal and chemical state at IVC and also on RCCI combustion.

The results discussion focuses on efficiency and $\mathrm{CH}_{4} / \mathrm{THC}$ emission reduction potential, in accordance with the study's main goal. The observed trends are further explained with the results of combustion analysis. The model, due its kinetic nature, also provides insight into the detail of species creation during the NVO phase. This is used to assess the chemical effects of fuel reforming.

\section{Methods and scope}

This section, discusses the details of the modeling. The model is based on the geometry of TNO's multi-cylinder RCCI engine platform, outlined in Subsection 3.2. The platform, with different hardware configurations, served for producing the experimental data necessary for calibrating and validating the model. The experimental operating points chosen as a basis for the present study are described in Subsection 3.3, together with the scope of the simulations. The results discussion adopts certain specific definitions of combustion, efficiency and emissions indictors which are 
used for post-processing of both experimental and simulation data. These definitions are discussed in Subsection 3.4.

\subsection{Modeling approach}

The present simulation study is based on TNO's inhouse model, referred to as XCCI. Its governing equations are described in the work of Bekdemir et al. [47]. For brevity, the discussion in this paper examines XCCI's main assumptions, with emphasis on functionalities relevant to the current research. Specific modifications were made to the baseline code for this study, so these are also described.

$\mathrm{XCCI}$ is a zero-dimensional, multi-zone approach adopting detailed chemical kinetics and phenomenological flow field modeling to reflect RCCI combustion. The multizonal construct stems from the need to represent thermal and fuel reactivity stratification occurring within the cylinder in typical RCCI combustion regimes. The current implementation employs a 13-zone configuration, with finer discretization near cylinder walls to better reflect the autoignition dynamics (Fig. 1). The zones are essentially cylindrical control volumes placed in a concentric arrangement. The control volumes vary in time and possess a unique temperature and concentration value, but share their pressure values with their neighboring volumes. This allows for direct mass and heat transfer between neighboring zones, with interactions governed by a gradient-based inter-zonal mixing model.

The system exchanges heat with the environment across the cylinder head, piston crown and cylinder liner The process is assumed to be convection dominated (gas to wall) with the heat transfer coefficient calculated from the formula by Chang et al. [48], calibrated explicitly for LTC combustion. XCCI adopts validated sub-models for estimating the gas-side temperatures of the individual cylinder components. The above interactions are illustrated schematically in Fig. 2.

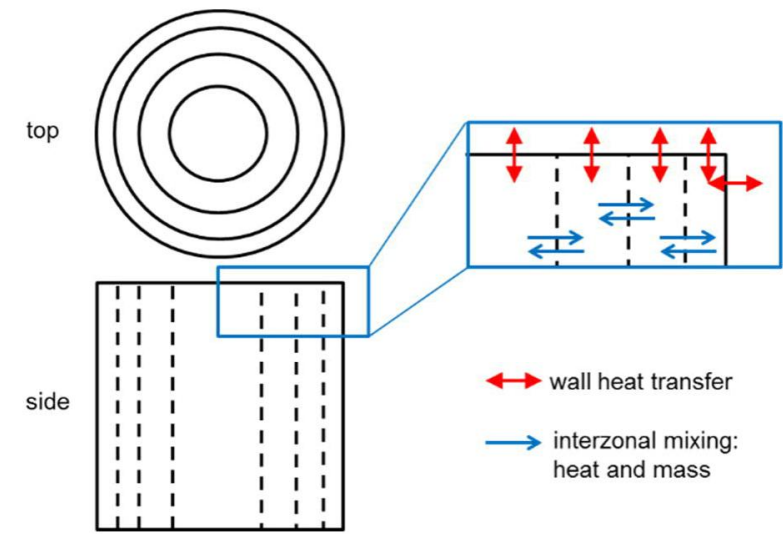

Figure 2: Graphical representation of the multi-zone model with cylindrical zonal configuration.

Gaseous fuel is assumed to be homogenously mixed with air and recycled exhaust gas at IVC. During the injection duration, liquid fuel is introduced to the individual zones in a predefined distribution pattern. This is set such that it closely resembles the fuel stratification within the cylinder as a result of the injection strategies used in this RCCI engine. Note that the injection model includes heat consumption due to fuel evaporation.
The combustion is assumed to be controlled by reaction kinetics. A combination of $\mathrm{n}$-heptane (diesel representative) and NG combustion mechanisms, incorporating a total of 65 chemical species is used. The nheptane combustion modeling follows the general scheme described in [49]. The $\mathrm{C}_{1}-\mathrm{C}_{3}$ part of this scheme is substituted by the GRI 3.0 [50] mechanism, which also provides the $\mathrm{NO}_{\mathrm{X}}$ formation reactions. This combined mechanism results in total of 354 partial reactions and proves to be an effective means to RCCI combustion (with various compositions of NG), wherein the effect of intermediate species is also taken into account. Furthermore, the simple hydrocarbons and radicals that are produced during the fuel reforming process, and are known to have significant effect on mixture ignitability [36] are present in this combined reaction mechanism. This inclusion assures the necessary functionality of the model to research the influence of NVO fuel reforming, not only apropos the dominant thermal effects [41], but also including the secondary effects related to chemistry. Note, however, that the reaction scheme was not validated quantitatively in terms of intermediate species formation.

RCCI combustion is very sensitive to IVC conditions. For instance, cycle-to-cycle changes in recycled exhaust gas composition (especially the unburned hydrocarbons and partially reformed intermediate species) ean substantially influence combustion and resulting performance indicators. This sensitivity is incorporated into the simulation model by means of a multi-cycle routine including the gas exchange processes across the valves. A valve flow model transfers the effect of valve motion to the processes in the combustion chamber and enables the variable valve actuation functionality. Consequently, both the intake and exhaust manifold compositions are refreshed after every simulation cycle, and the simulation is run until a convergence in resulting pressure trace is reached. The simulation scheme including relevant inputs and main outputs of the XCCImodel is shown Fig. A1 (Appendix A).

Slight modifications were made to the model for the present investigation, so it is not exactly the version discussed in [47]. The model now includes a separate independently operated closing valve (IOCV) in the intake port ( $\left.\mathrm{IOCV}_{\text {int }}\right)$ to reproduce the current VVA hardware configuration of Phase II (see Subsection 3.2 for details). In order to provide additional freedom in achieving the desired valve configuration, the same element was added to the model's exhaust side $\left(\mathrm{IOCV}_{\mathrm{exh}}\right)$. Note that the IOCV-based VVA hardware component is present only on the intake side in the Phase II setup while the simulation model described here distinguishes the same component modeled on the intake and exhaust sides of the engine as $\mathrm{IOCV}_{\text {int }}$ and $\mathrm{IOCV}_{\text {exh. }}$. Both IOCV elements are modeled as constant volume reactors between the original engine valves and respective manifolds (Fig. A1 - Appendix A). The detailed air-path geometry is not considered in the simulation model. Note however, that the volume of the intake reactor was tuned to the experimental data to capture the effect of backflows correctly, without considering the full air-path dynamics. Furthermore a dedicated procedure is implemented to track the backflow composition and ensure that all of the relevant species are reaspirated at the following cycle, as in a real engine. 
During the gas exchange processes, the combustion chamber is simulated as a single zone reactor for computational efficiency reasons.

Since the NVO phase and the effects of direct fuel injection during this period are of particular interest, the NVO period is simulated in exactly the same detail as the main combustion phase described earlier. Specifically, the 13-zone configuration with inter-zonal mixing and direct injection capability is employed throughout the NVO and main combustion phases.

\subsection{Experimental setup and calibration methodology}

The engine platform considered here is a heavyduty, six-cylinder diesel engine that has been modified for RCCI operation using diesel and natural gas. This platform was first introduced by TNO in the work by Doosje et al. [5] in 2014, and since then has undergone numerous hardware modifications with the aim to optimize combustion and extend the engine-load range. The present work relies on two hardware versions, referred to here as Phases I and II. Both hardware versions are compared in Table 1

Table 1. Basic technical data of the TNOs RCCI engine platform in development Phases I and II.

\begin{tabular}{|l|l|}
\hline Engine Type & Heavy-duty, six-cyl. in line, $300 \mathrm{~kW}$ (in diesel mode) \\
\hline $\begin{array}{l}\text { Compression } \\
\text { ratio }\end{array}$ & $14: 1$ (geometrical) \\
\hline Fuel path 1 & $\begin{array}{l}\text { Diesel: Standard EN590, cetane number }=52, \mathrm{LHV} \\
42.7 \mathrm{MJ} / \mathrm{kg}, \text { common-rail system, split injection } \\
\text { capability }\end{array}$ \\
\hline Fuel path 2 & $\begin{array}{l}\text { Dutch Natural Gas: } \mathrm{LHV}=38 \mathrm{MJ} / \mathrm{kg},\left[\mathrm{CH}_{4}\right]=82 \%, \\
{[\mathrm{~N} 2]=14 \%,[\mathrm{NMHC}]=4 \%,}\end{array}$ \\
\hline EGR path & High-pressure, cooling, valve, variable bypass \\
\hline $\begin{array}{l}\text { Hardware } \\
\text { configuration }\end{array}$ & Phase I \\
\hline
\end{tabular}

\begin{tabular}{|c|c|c|}
\hline $\begin{array}{l}\text { Piston bowl / } \\
\text { injector } \\
\text { config. * }\end{array}$ & & \\
\hline Gas injection & $\begin{array}{l}\text { SPI with mixer after } \\
\text { turbocharger }\end{array}$ & $\begin{array}{l}\text { PFI to individual cylinder } \\
\text { ports }\end{array}$ \\
\hline Air path & Single stage turbocharger & $\begin{array}{l}\text { Sequential turbo, intake } \\
\text { throttle, IOCV valve }\end{array}$ \\
\hline IVO/IVC & $-25 / 215 \mathrm{CA}(\mathrm{aTDC}) * *$ & Flexible with IOCV \\
\hline $\mathrm{EVO} / \mathrm{EVC}$ & $-235 / 30 \mathrm{CA}(\mathrm{aTDC}) * *$ & $-235 / 30 \mathrm{CA}(\mathrm{aTDC})^{* *}$ \\
\hline Remarks & $\begin{array}{l}\text { Model calibration and } \\
\text { non-EGR baseline for the } \\
\text { present study. }\end{array}$ & $\begin{array}{l}\text { Model validation (VVA } \\
\text { functionality) and hot- } \\
\text { EGR baseline. }\end{array}$ \\
\hline
\end{tabular}

*schematic diesel spray pattern for different piston geometries at same SOI. ** TDC value used here refers to the gas exchange period (referred to as NVO TDC). Consistently, all the CA references used in this paper use this point as a base $(0 C A=N V O T D C)$.

Phase I was extensively used for the purpose of XCCI model calibration in the earlier works by the authors [9]. The obtained calibration is incorporated in the present work. Additionally, Phase I applied a non-EGR strategy for realizing RCCI under low-load conditions and thus serves as a baseline for the current research in this regime.

Phase II incorporates a variable intake valve system, using solenoid-based plate valves placed in individual cylinder ports. The system, referred to as IOCV (independently operated closing valve), can be used to achieve the effects of both late intake valve opening and early intake valve closing, individually for each cylinder with actuation times allowing for in-cycle control. The associated changes to the hardware include replacement of Phase I's single point Compressed Natural Gas (CNG) injection system by multipoint injectors located in individual intake ports. The gaseous fuel is introduced between the IOCV and the standard intake valve during its opening window. The air path has been modified to facilitate the heavy EGR strategy, with higher boost pressures necessary for combination with reduced intake opening times. This was achieved with a two-stage turbocharging system capable of producing boost pressures of up to 4.5 bars. The Phase II configuration is used to test the model's VVA functionality and to serve as a baseline for simulating the lowload RCCI regime with large external EGR ratios.

Note that the injector/piston arrangements of the two phases are significantly different. In Phase I, a flat piston and stock diesel injectors are used (see Table 1 for details). In contrast, Phase II realizes RCCI with a re-entrant shape piston bowl with increased squish. This is coupled with a new axisymmetric injector with narrower spray angles to facilitate early injection events. The fuels used in both cases are standard: commercially available diesel fuel with properties according to the EN590 standard and compressed natural gas from the grid with heating value of approximately $38 \mathrm{MJ} / \mathrm{kg}$.

The same test-bench measurement protocol is applied for both hardware configurations. The measured signals are used for model calibration (Phase I) and validation (Phases I and II). Manifold pressure, temperature and intake mass flow rates are measured and used to calibrate the model's charge exchange process. For the combustion part, Kistler type 6056 piezoelectric sensors coupled with the charge amplifier are used to measure instantaneous ineylinder pressure. The CA-based signals from all cylinders are recorded using AVL's indication system.

3 Model calibration is performed via an automated procedure based on minimizing the residual error between experimental and simulated pressure traces. Validation is performed by comparing the results of the model calculation and experimental results, in terms of in-cylinder pressure trace and heat release rate (HRR). Additionally, several combustion indicators and engine-out emissions indexes (NO, $\mathrm{NO}_{\mathrm{X}}, \mathrm{THC}, \mathrm{CO}$ ) are used to help determine the model's validity. Using exhaust gas sampling downstream of the turbine, the individual species concentrations are recorded with a Horiba MEXA series analyzer. Additionally, $\mathrm{CO}_{2}$ concentration measurements in the intake manifold are used to determine the external EGR rates that serve as a model input. The next section provides the necessary information on how the individual parameters, used for both validation and current research, are calculated. More information on the measurement system, the calibration and validation procedures can be found in the work by Mikulski et al. [51].

\subsection{Calculation Methodology}

The results discussion is based on several combustion indicators that are post-processed from the raw simulation results, being the zonal-averaged in-cylinder conditions (pressure, temperature and detail composition given as mass fractions of individual species in the mechanism) at each CA instance. Note that the same processing methodology is used for both the simulation and 
experimental results if such are presented (model validation). This section outlines the definitions that are specific to the present work.

An RCCI operating point, except standard engine parameters like engine speed, EGR ratio or air-fuel ratio $(\lambda)$, is defined by a certain blend rate (BR) of low and high reactivity fuel. The present work consequently adopts the energy-based definition of this parameter given by Eq. 1 .

$$
B R=\frac{\dot{m}_{N G} L H V_{N G}}{\dot{m}_{\text {diesel }} L H V_{\text {diesel }}+\dot{m}_{N G} L H V_{N G}} .
$$

The terms in Eq. 1 stand for mass flow rates $(\dot{m})$ and lower heating values (LHV) of NG and diesel, respectively.

HRR is calculated from both the simulated and experimental pressure traces in the same manner, using a standard procedure based on the first law of thermodynamics [52]. A constant ratio of specific heats $(\gamma=1.37)$ is applied. The net HRR is corrected with the heat transfer to the walls (calculated from the model) to give the gross HRR, which is presented in the following sections, for the main combustion event. Furthermore, the gross HRR serves as the basis for the calculation of cumulative heat release (CHR) and determination of CA10 and CA50 (crank angle at 10\% and $50 \%$ heat released, respectively). Note that the CHR is also used in the present work to access the thermal effects of NVO fuel reforming. The NVO CHR is obtained in the same manner as for the main cycle, yet does not take heat loss into account.

The gross and net IMEPs are calculated by integrating the pressure signal through the closed part of the cycle (from IVC to EVO) and across the whole $720 \mathrm{CA}$ respectively. Consequently, the corresponding gross and net indicated efficiencies are used in this study and defined as:

$$
\eta_{\text {gross } / \text { net }}=\frac{1 / 2 \cdot \mathrm{IMEP}_{\text {gross } / \text { net }} \cdot V_{\text {disp }} \cdot N}{\dot{m}_{\text {diesel }} L H V_{\text {diesel }}+\dot{m}_{N G} L H V_{N G}}
$$

where $V_{\text {disp }}$ is the displacement volume and $N$ denotes engine rotational speed.

Concentrations of species such as $\mathrm{NO}_{X}, \mathrm{CH}_{4}$ and $\mathrm{CO}$ are analyzed in the present work on a volume basis. Simulated emissions are calculated from the zone-averaged cylinder composition at EVO. The concentrations of individual hydrocarbons and $\mathrm{CO}$ at this point are taken to calculate combustion efficiency. This is done with the simplifying assumption that all of the unburned $\mathrm{HCs}$, except the $\mathrm{CH}_{4}$, account to diesel fuel particles. Then, the combustion efficiency becomes:

$$
\eta_{\text {comb }}=1-\frac{\dot{m}_{C H_{4}, \text { res }} L H V_{C H 4}+\dot{m}_{C O, \text { res }} L H V_{C O}+\dot{m}_{N M H C, \text { res }} L H V_{\text {diesel }}}{\dot{m}_{\text {diesel }} L H V_{\text {diesel }}+\dot{m}_{N G} L H V_{N G}}
$$

where $\dot{m}$ terms with subscripts: " $\mathrm{CH}_{4}$,res", "CO,res", and "NMHC,res" represent the concentrations of the corresponding species at EVO recalculated with the total exhaust flow rate to the adopted convention of mass flow as in Eq. 1 and Eq. 2.

Consequently, the concentrations of various species in the kinetic mechanism are analyzed (in Subsection 4.5) to assess the chemical effects of NVO fuel reforming. These are taken directly from simulation results as in-cylinder, zoneaveraged mass fractions given at defined CA instances (IVO and IVC in this case).

\subsection{Scope of the research}

Two experimental cases serve as a baseline for the present simulation study. Both selected test cases are lowload operating point (IMEP around 3 bar) with the same engine speed of $1000 \mathrm{rpm}$. This load point reflects the research objective: as stated in the introduction, low-load conditions are challenging for NG-diesel RCCI due to low combustion efficiency resulting in excessive methane slip. y Relatively high amounts of diesel typically are required to initiate ignition and maintain fuel reactivity distribution for proper combustion propagation under these conditions [9]. This is confirmed in Table 2, where the operating conditions for both cases are provided. One can note that the BRs (Eq. 1) for cases $\mathrm{A}$ and $\mathrm{B}$ are $50 \%$ and $60 \%$, respectively.

Table 2. Baseline test case operating parameters relevant to the present study.

\begin{tabular}{|l|c|c|c|c|c|c|c|c|}
\hline $\begin{array}{l}\text { Case / } \\
\text { hardware }\end{array}$ & $\begin{array}{c}\mathrm{N} \\
{[\mathrm{rpm}]}\end{array}$ & $\begin{array}{c}\text { IMEP } \\
{[\mathrm{bar}]}\end{array}$ & $\begin{array}{c}\mathrm{BR} \\
{[\%]}\end{array}$ & $\begin{array}{c}\text { SOI } \\
{[\mathrm{CA}]}\end{array}$ & $\begin{array}{c}\text { EGR } \\
{[\%]}\end{array}$ & $\begin{array}{c}\lambda \\
{[-]}\end{array}$ & $\begin{array}{c}\mathrm{T}_{\text {int }} \\
{[\mathrm{K}]}\end{array}$ & $\begin{array}{c}\mathrm{P}_{\mathrm{int}} \\
{[\mathrm{bar}]}\end{array}$ \\
\hline $\begin{array}{l}\text { Case A } \\
\text { Phase II }\end{array}$ & 1000 & 3 & 50 & 325 & 57 & 1.6 & 363 & 1.12 \\
\hline $\begin{array}{l}\text { Case B } \\
\text { Phase I }\end{array}$ & 1000 & 3.2 & 60 & 310 & 0 & 2.8 & 333 & 0.95 \\
\hline
\end{tabular}

Case A was realized on Phase II's hardware configuration, which allowed large amounts of external, uncooled EGR to elevate the intake temperature. This is considered an important factor to promote complete combustion. At the same time, excessive EGR reduces the overall mixture reactivity and thus enables keeping the combustion phasing in-line while the temperature is elevated.

Case B represents the opposite approach to low-load RCCI operation, with no external EGR. Instead, it uses high lambda operation, which, along with the intercooler bypass, allows attainment of intake temperatures sufficiently high for RCCI mode. This strategy was investigated experimentally by TNO on Phase I hardware.

It is evident that both cases have fundamentally different operating characteristics and utilize different hardware functionalities. They are thus used to support different aspects of the current research. Table 3 provides an overview of the individual endeavors performed to support the study's thesis. 
Table 3. Scope of the present research along with the values of the parameters being swept. All crank angle values are specified with the exhaust/firing TDC as the reference for $C A=0$. CA range: -720 to +720 , through 0 at exhaust/firing TDC (around NVO phase).

Since Phase II was incorporated with the IOCV valves, Case $\mathrm{C}$ $A$ is used to demonstrate the VVA functionality of the XCCI model. This is based on the intake valve opening sweep which was performed both experimentally and by means of simulation. Case A further served as the baseline for determining the NVO valve configuration for the present research. This was done by adjusting the exhaust valve opening and closing angles, aiming to attain NVO recompression temperatures sufficient to trigger fuel reforming. At the same time, the IVO was adjusted in order to provide sufficient NVO window for the reactions to proceed. After determining the desired valve configuration for exhaust gas recompression, the effects of NVO fuel injection are investigated in Cases A and B respectively. This is done by varying mass of injected fuel to retained residuals for chosen injection timings, and vice versa. The mass split ratio (MSR) is varied from $10 \%$ to $50 \%$, while the diesel pilot start of injection $\left(\mathrm{SOI}_{1}\right)$ is varied across the whole spectrum of NVO period (in this case from -38 to $5 \mathrm{CA}$ ). For all parameter sweeps discussed here (Table 3) the initial conditions are the same as for the two baseline cases (see Table 2). Note however that the intake manifold conditions (temperature and composition) are updated during the simulation, based on the subsequent cycles' results (refer to subsection 3.1 for details).

\section{Results}

The latest iteration of the XCCI model, which includes the VVA-related modifications, was tested for its predictive capabilities for the two test cases on the available test platform. The results of this validation, along with the methods used to assess performance, are discussed in Section 4.1. Then, Section 4.2 discusses the preliminary simulation study performed to understand engine behavior when operating with reduced valve overlap. The observed tradeoffs in common engine performance indicators guided the selection of NVO configuration for subsequent tests. More importantly, Section 4.2 also presents the results of the simulations performed on the two operating points (A and B) to demonstrate the potential of fuel reforming within the trapped residuals during the NVO period (resulting from adopted valve profiles as shown in Section 4.2). The two lowload operating points are assessed individually for overall engine operation through a selection of relevant parameters. These simulation results are discussed on a per parameter basis in Section 4.3. To fully understand the consequential changes in engine operation, both the thermal (Section 4.4) and chemical effects (Section 4.5) of NVO fuel injection are analyzed and examined in detail. Results are discussed for the parameters that hold significance for the observed trends. Finally, section 4.6 discusses the combined results, aiming to form a coherent view of NVO-RCCI technology and assess its applicability.

\subsection{Baseline cases and model validation}

As discussed earlier, the XCCI model was tuned to the engine configuration referred to as Phase I. This did not include the IOCV functionality. The results of the baseline model calibration are discussed for Case B in Fig. 3. For the purpose of the VVA research (present paper and previous work by the authors [21]), the XCCI model was further extended with the VVA functionality. This extension involved additional control volumes in the valve flow sub model as discussed in subsection 3.2. Thus, Fig. 3 shows traces (for the in-cylinder pressure, the instantaneous and cumulative heat release rate, respectively) for three scenarios: the experimentally recorded signals and the results of the two 
simulations i.e. baseline and VVA- extended model, with the same tuning.

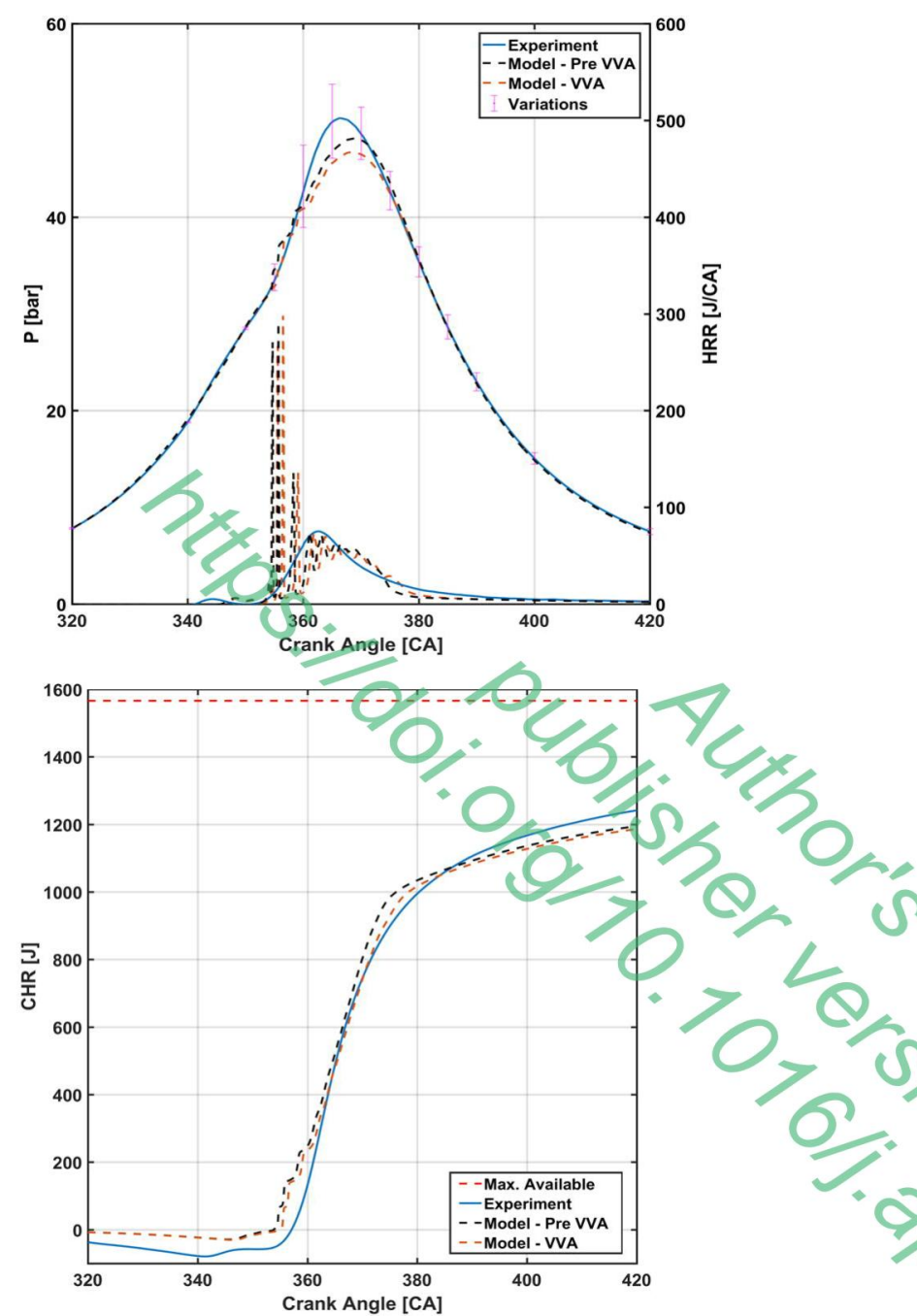

Figure 3. Comparison of experimental (solid line) and simulated (dashed lines) in-cylinder pressure and HRR and CHR for the baseline case B (Table 3). Calibrated XCCI model results (black dashed line) and the results after extension towards VVA functionality (orange dashed line).

It is evident from Fig. 3 that the baseline calibration of the XCCI model can capture the experimental in-cylinder pressure within cylinder-to-cylinder variations, which was the criterion for the model tuning. Despite the fact that the adopted kinetic mechanism predicts pre-ignition reactions later than ones observed on the experimental HRR trace (first peak on the experimental HRR trace), the actual start of combustion is slightly earlier for the modeled case. Note that the "spiky" behavior of the simulated HRR, along with locally high peak values, is the result of modeling's zonal nature. Note, however, that the combustion process is captured accurately, borne out by the traces of cumulative heat release. Also, the gap between the value of CHR at the end of expansion and the total energy introduced to the system with the fuel is predicted well, and illustrates the low combustion efficiency (Eq. 3) of the given case. This issue is characteristic of NG-diesel RCCI operated on low loads [21]. For extensive model tuning results for the Phase I hardware, including the combustion phasing and emission results for the discussed case, the reader is referred to one of the earlier works by the authors [9], [47].

The dashed orange line in Fig. 4 illustrates the results of Case A (Phase II hardware) re-simulated using the extended model with an additional control volume in the intake port to represent the IOCV valve. Note that no retuning was performed in this case and the IOCV valve was kept fully open across the whole IVO opening. One can note that the results of the simulation follow the same trend as for the baseline model. The HRR shape is almost identical in both cases, yet the start of combustion is slightly retarded (around $0.4 \mathrm{CA}$ ) for the IOCV realization. This is the result of minor differences in the filling efficiency, with the additional valve unit somewhat obstructing the flow. Note that LTC combustion exhibits high sensitivity to IVC thermal state and mixture composition [9], [41]. The impact on overall combustion indicators is around $2.5 \%$ reduced peak pressure value and similar reduction in IMEP, stemming from lower amount of gaseous fuel trapped in the cylinder. Note that the $\mathrm{BR}$ recomputed (Eq. 1) on the basis of IVC composition was correspondingly increased, confirming the above conclusion.

The above trends in the effect of IOCV volume implementation are fundamentally correct and in line with common knowledge. The validity of the adopted VVA implementation can further be confirmed when the corresponding architecture is tested experimentally. This is shown in Fig. 4 where the low-load RCCI operation has been realized for the Phase II configuration (Case A). This case represents the high EGR strategy with high boost and fully opened IOCV valve. One can note that combustion efficiency is significantly improved in Case A (compare CHR plots in Figs. 3 and 4), which is mainly the effect of elevated IVC temperature using hot, external EGR and increased turbulence (boost and increased squish). Note that the difference in $\mathrm{T}_{\text {IV }}$ between the two cases is about $30 \mathrm{~K}$. With the elevated temperature for Case $\mathrm{A}$, the correct combustion phasing is maintained by decreased mixture reactivity through EGR and additionally by application of later injection timings with decreased BR. The relevant combustion indicators are shown in Fig, 5. Apart from improved combustion efficiency, a comparison of the experimental pressure traces in Figs. 3 and 4 reveals significantly reduced cylinder-to-cylinder variations for Case A. This is mainly attributed to the PFI gas injection system introduced in the Phase II hardware, giving more accurate (compared to the SPI system used in Phase I) control of gaseous fuel introduced to individual cylinders. 

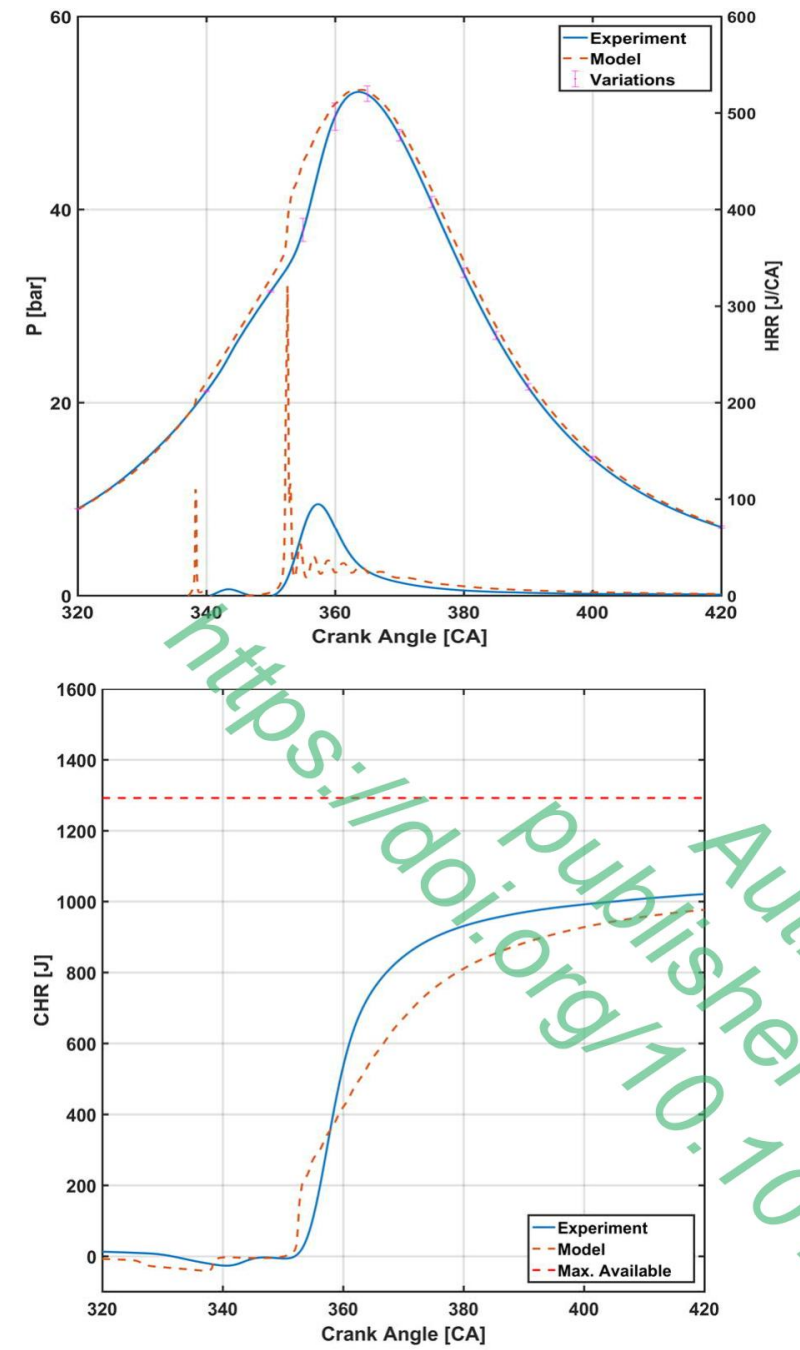

Figure 4. Comparison of experimental and simulated incylinder pressure and HRR and CHR for the baseline case A - fully opened IOCV (Table 3). The simulation results (orange dashed line) refer to the model with VVA functionality with Phase I tuning.

Figure 3 shows the results of the XCCI model with VVA functionality along with the corresponding experimental data, depicting in-cylinder pressure and HRR. Despite different piston shape and injector configuration, the model tuned for Phase I was able to represent the in-cylinder pressure trace accurately, though the start of combustion is slightly faster with the heat release being overestimated at the beginning of the combustion and understated towards the later phase. This discrepancy is mainly associated with the fact that the same zonal configuration, originally designed for Phase I, was used to simulate Phase II, without re-tuning. Note that the latter case manifests more complex cylinder geometry-related effects which are not captured by the simple, cylindrical zone configuration adopted in the current XCCI setup (compare Table 1). Still, the combustion efficiency is captured correctly with similar discrepancies in the cumulative heat released comparable to Case A.

The overall performance of the model in both base cases A and B is well illustrated by selected combustion indicators and emission results presented in Fig 5, cumulatively with the IOCV opening sweep around Case A. Since this valve strategy is used to shape NVO in the present research, it is selected to showcase the model's ability to reproduce changes in valve actuation. Note that this particular realization of late IOCV opening is intended to keep excess air and all other fueling parameters constant, so intake pressure is increased commensurately with the reduction of the effective IVC window. Consequently, any effect of the strategy on the combustion is correlated with two factors: increased exhaust valve backflow (increased internal EGR) and increased intake valve flow velocity (effecting turbulence). The specific valve settings investigated for this sweep are illustrated in Fig. 6.
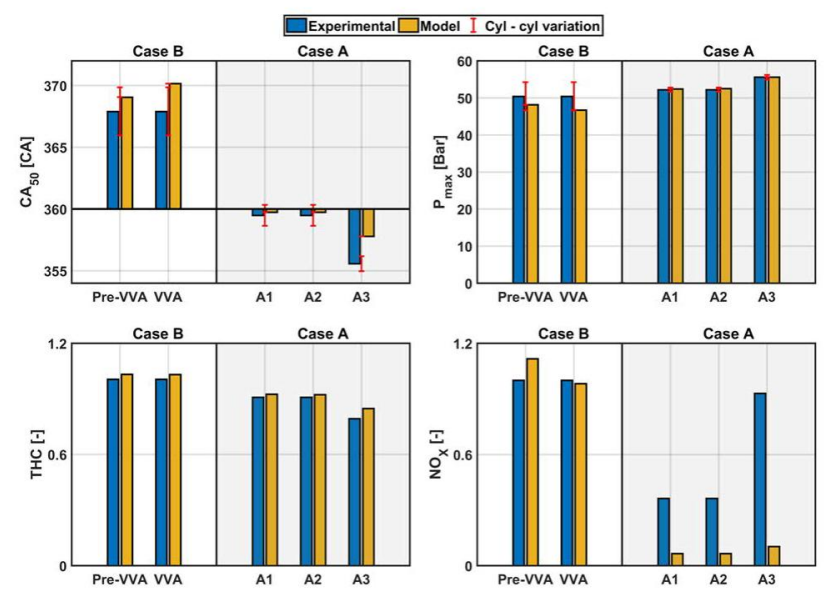

Figure 5. Selected combustion and emission indicators calculated for the experimental and simulation results for all validated points. Emissions are given as relative values with respect to the baseline Case $B$.

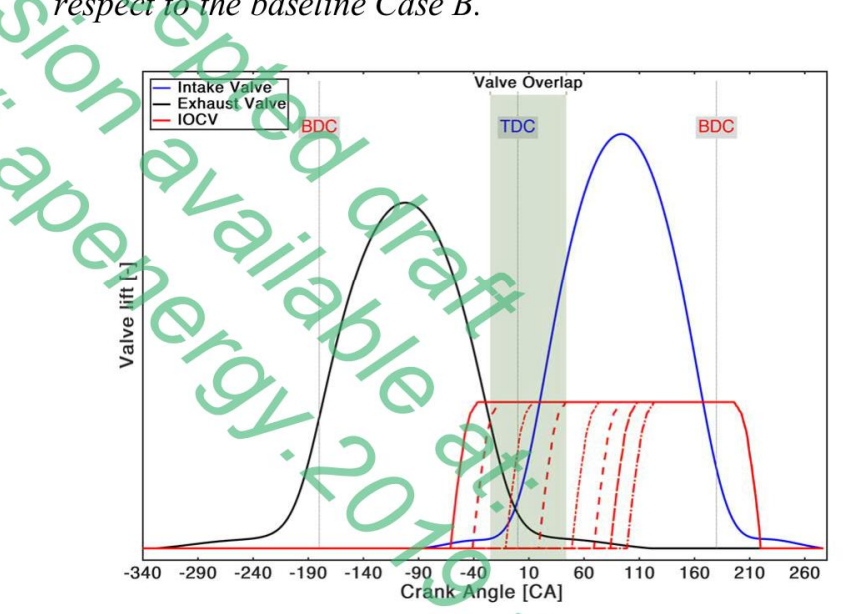

Figure 6. Valve settings for the IOCV sweep around Case A investigated in this section. The particular IOCV profiles indicated in red dashed lines correspond to subsequent subcases in Fig. 5.

The results presented in Fig. 5 for Case A, for which the model was tuned, confirm the observations made on the basis of in-cylinder pressure analysis (Fig. 4). Relevant combustion indicators are predicted within cylinder-tocylinder variations and emissions are predicted with satisfying accuracy. Results from base case B show considerably less accuracy in terms of combustion phasing than Case A's results. This is understandable due to the fact that the operating point itself and the cylinder geometry were not included in the tuning procedure.

The IOCV closing sweep does not have significant influence on either the combustion characteristics or the emissions until the IVO is prolonged beyond the valve overlap period (Fig. 6 ). This because in this particular region the exhaust valve 
flow dominates the in-cylinder condition forming (backpressure in the exhaust line). For IOCV opening at 30 $\mathrm{CA}$, combustion is significantly accelerated, raising peak pressure and $\mathrm{NO}_{\mathrm{X}}$ emissions and reducing THC emissions. The reasons for such behavior have been discussed in detail in the earlier work by the authors [21], identifying increased IVC temperature as the main driving force for the observed effects. At this point, the important observation is that the model can predict the correct trends with VVA, as evident in Fig. 5. The initial error in CA50 prediction is maintained, yet the simulation results show the reduction of CA50 for IVO = $100 \mathrm{CA}$ consistent with the experimental results. Looking at Fig. 5's $\mathrm{NO}_{\mathrm{X}}$ emission plot, the prediction inaccuracy of the XCCI model seems large for the VVA sweep. Note, however, that $\mathrm{NO}_{\mathrm{X}}$ emissions for low-load RCCI are already ultra-low. In fact, the recorded concentrations of $\mathrm{NO}_{\mathrm{X}}$ do not exceed 30 ppm in any of the presented cases, implying that the absolute difference between the model prediction and experimental results are close to the NOx measurement accuracy. Still the trends with VVA sweep for the $\mathrm{NO}_{\times}$exhaust concentrations are captured well. In both experiment and simulations the increase in this emission indicator, between VVA case A1 and $\mathrm{A} 3$, is $110 \%$ and $100 \%$ respectively.

For consistency reasons, the validation results are narrowed down to the discussed base cases A and B. Formore information regarding model validity, the readers are referred to the earlier publications by the authors $[9,46]$. Additionally, the model's VVA functionality has been investigated and validated on the handful of other operating points in Mikalski et al. [21]. The above considerations allow the authors to conclude that the discussed model is able to provide the qualitative view into the trends related to NVO operation achieved via VVA. The model's detail in terms of reaction kinetics allows the assumption that chemical effects associated with fuel reforming during NVO can be predicted with sufficient accuracy. Thus, the overall thermal and chemical effects of RCCI incorporating NVO can be assessed with the adopted approach. This in turn means it is possible to identify the qualitative potential of such measures for lowload RCCI efficiency improvement, which is the main goal of the paper.

\subsection{Effects of NVO on engine operation}

This section describes the process of VVA profile selection that is favorable to demonstrate the effects of chemical reforming of fuel when injecting into the trapped residuals, The requirements for a suitable VVA strategy for NVO fuel reforming are: clevated in-cylinder thermal statc during the NVO period, sufficient trapped residuals, and also, if possible, lowest penalties on engine efficiency [53]. Incylinder temperatures in the range of 700-1000 K have shown to initiate exothermic reactions in the fuel species [41]. For the reacting species to undergo chemical reformation, higher internal EGR is preferred, since it provides more of the reforming substrates. The NVO configuration adopted for the operating points described here, although perhaps not the ultimately optimized configuration, is one that aims to meet the requirements set out above, albeit with some trade-offs, illustrated below.

Preliminary trials with both symmetric and asymmetric NVO configurations provided guidelines for the final adopted configuration. The symmetricity mentioned here pertains to the shift in valve profiles, not the location of the NVO period with respect to exhaust TDC. Ideally, an NVO period distributed equally on both sides of TDC is the least detriment for total engine work output because the compression and expansion strokes are of equal length.

\subsubsection{Symmetrical NVO by shifting exhaust and intake valve profiles.}

In the engine platform used in the current research, the interval between NVO TDC and IVO is quite small, so a significant shift of the intake valve profile is required to achieve symmetry in NVO around this TDC. Figure 7 shows the in-cylinder pressure traces for an initial NVO sweep performed on Case A. In this sweep, the intake valve is retarded and the exhaust valve was advanced respectively, in equal steps, giving NVO periods of 20,40, 60, 80 and 100 $\mathrm{CA}$ in width. The IOCVs are set to remain fully open when the engine's valves are open and therefore do not influence the gas exchange processes.

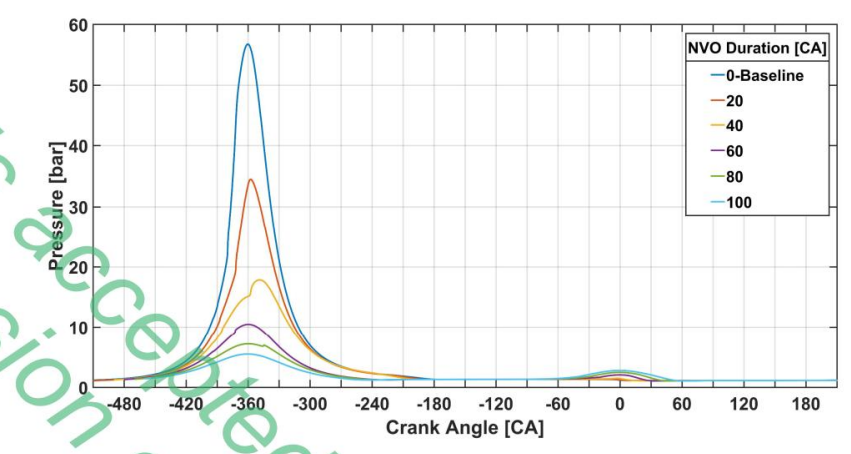

Figure 7 In-cylinder pressure trace for initial NVO sweep with both intake and exhaust valve profiles shifted.

Figure 7 suggests that stable combustion cannot be maintained with an NVO period greater than $20 \mathrm{CA}$ due to a large reduction in compression pressure. Therefore, shifting the intake valve's profile later by more than $10 \mathrm{CA}$ necessitates reduction of the intake valve opening period to maintain required thermodynamic compression ratio.

\subsubsection{Asymmetrical NVO by advancing the exhaust valve profile.}

Following the approach in 4.2.1, further NVO shaping focuses on the exhaust valve's profile, advancing it in steps of $10 \mathrm{CA}$ up to $80 \mathrm{CA}$ from the baseline, with the intake valve's profile maintained at the default configuration. Both the IOCVs are fully open, as in 4.2.1, so only the change in EV profile influences NVO duration. Figure 8 shows that in this sweep, all cases show acceptable combustion characteristics and crucially, demonstrate the potential for meeting thermal state targets during this secondary compression phase. 


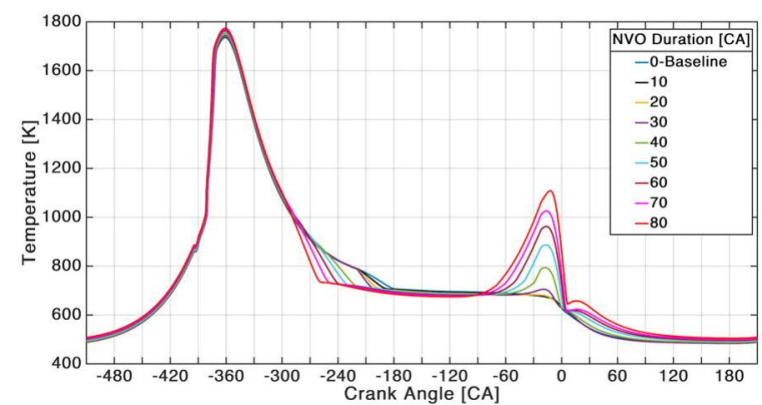

Figure 8. Temperature trace for second NVO sweep with only the exhaust valve's profile phase shifted.

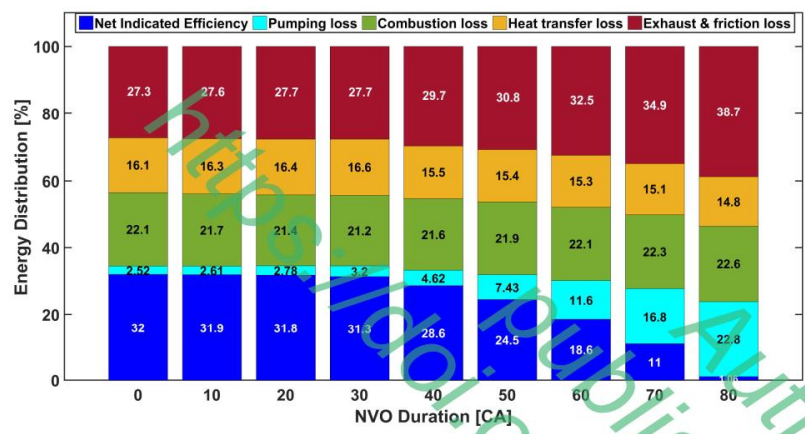

Figure 9. Energy balance for NVO sweep, wherein the asymmetrical NVO was achieved by advancing the EV profile only.

Points in the sweep with NVO duration of $40 \mathrm{CA}$ and above show peak in-cylinder temperatures of at least $800 \mathrm{~K}$ during the NVO period, sufficient to trigger fuel reforming reactions. However, for cases with the exhaust valve profile advanced significantly, the maximum operating point (MOP) of the exhaust valve inevitable lies in regions that are not favorable for the work output. The energy balance shown in Fig. 9 demonstrates that advancing the exhaust valve profile reduces main event work output due to shortening of the power stroke. It also increases exhaust temperature, contributing to exhaust losses. Finally, as NVO asymmetry increases (in this case by extending the NVO duration solely by EV profile advancing), the work input of the gas exchange period, including NVO, also increases, indicated as pumping losses in Fig. 9.
4.2.3 Selected NVO configuration: Combination of advanced exhaust valve profile with IOCVs.

With the information from preliminary tests described in 4.2.1 and 4.2.1, the following NVO configuration is chosen for both cases (A and B) in this study. The exhaust valve's profile is advanced by $35 \mathrm{CA}$ from the baseline and the intake valve's default profile is retained. In addition, the IOCVs are used to effectively widen the NVO window. The IOCV at the exhaust side is set to close at -40 $\mathrm{CA}$, giving earlier EVC. The IOCVs in the intake ports are set to open at $10 \mathrm{CA}$, enabling late IVO. The chosen configuration, illustrated in Fig. 10, provides sufficient NVO temperature increase, with an acceptable efficiency penalty.

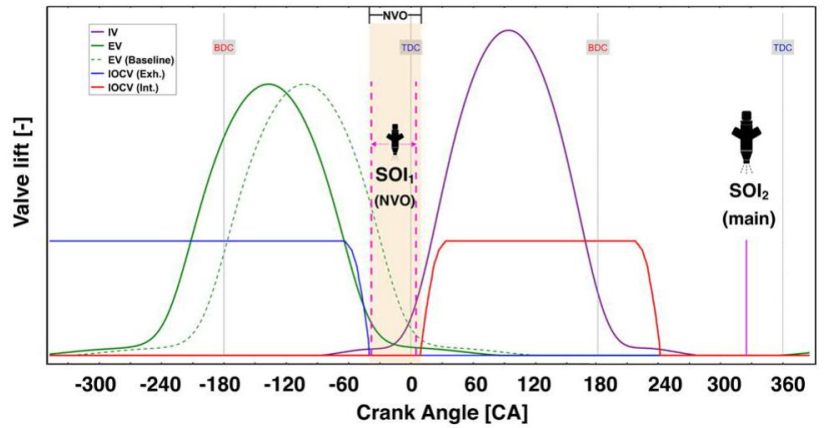

Figure 10. Valve lift profiles selected for reference NVO operation vs the baseline PVO case. Fuel injection windows used in the present research are highlighted.

The light pink shaded region in Fig. 10 shows the NVO period. This is the available window for introducing pilot fuel injection $\left(\mathrm{SOI}_{1}\right)$ to achieve reforming effects. $\mathrm{SOI}_{1}$, therefore, can be varied from $-40 \mathrm{CA}$ to $+10 \mathrm{CA}$.

4.2.4 Effects of the selected NVO strategy on low-load combustion.

The two baseline low-load cases (A and B) are simulated with the NVO configuration outlined in 4.2.3. The combustion analysis provides reference values for the fuel injection tests discussed in the following sections of this paper. The results are shown in Fig. 11.
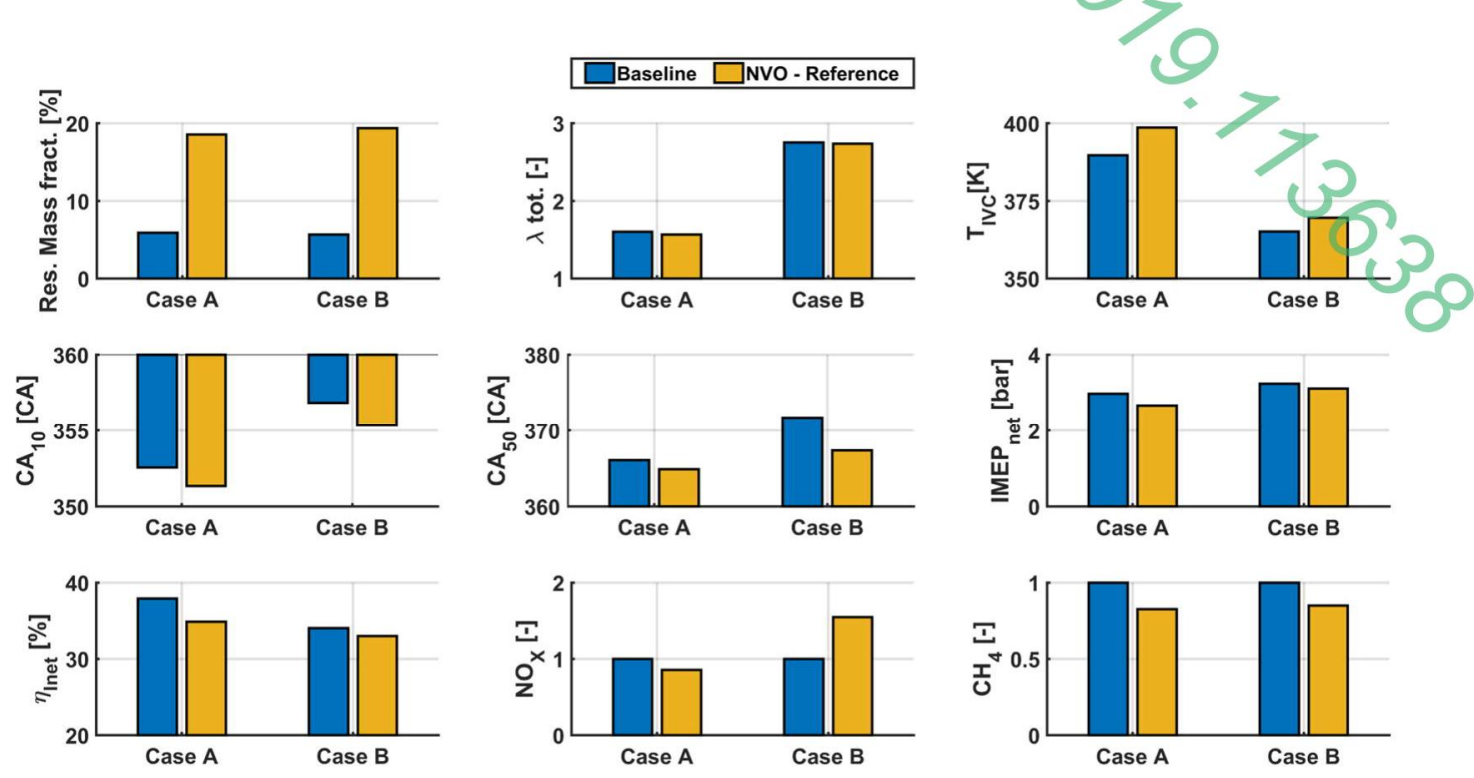

Figure 11. Comparison of baseline PVO (blue) and reference NVO cases (yellow). Emissions are given as relative values with respect to the individual baselines. 
One can observe that the application of NVO has major effects on mixture state at IVC in both RCCI regimes. The Residual Mass Fractions (RMF) increase from 5\% to almost $20 \%$. Note however, that the total $\lambda$ for the two cases (around 1.6 and 2.8 for Cases A and B respectively) remained roughly unchanged with the introduction of NVO. This suggests that the volumetric efficiency of the intake process is only marginally reduced from the baseline conditions, despite large-scale differences in the amounts of trapped residuals.

The direct result of trapping hot combustion products in the cylinder is the increase in the bulk mixture temperature at IVC. NVO enables $\mathrm{T}_{\text {IVC }}$ increases of around $10 \mathrm{~K}$ and $6 \mathrm{~K}$ in hot EGR and lean RCCI low-load cases respectively. The elevated $\mathrm{T}_{\mathrm{IVC}}$ level is the main reason for the slight increase in combustion efficiency (Eq. 3). This, together with the effect of increased charge dilution, translates to around $15 \%$ reduction in exhaust $\mathrm{CH}_{4}$ concentrations. Those two effects (increased $\mathrm{T}_{\mathrm{IVC}}$ and increased internal EGR) at the same time counteract each other in terms of mixture ignitability and the rate of combustion propagation, allowing proper combustion phasing for case A and B's NVO configurations Note that the CA10 and CA50 timings are only slightly accelerated for the NVO strategy.

$\mathrm{NO}_{\mathrm{x}}$ concentration is not affected by the introduction of NVO in the heavy EGR strategy (Case A) but NOx concentration increases by over $50 \%$ percent for the lean strategy (Case B). However, due to ultra-low bassline $\mathrm{NO}_{\mathrm{X}}$ emission, this result is still below Euro VI's $0.4 \mathrm{~g} / \mathrm{kWh}$ limit.

On the other hand, the shortened power stroke and increased load on the piston during the compression stroke in the NVO period penalizes net IMEP $\backslash$ as well as indicated thermal efficiency $\left(\eta_{\text {Inet }}\right)$ (Eq. 2). The penalty is, however, far less pronounced for the lean strategy. For instance, the pumping losses with the lean strategy reach $3.5 \%$, versus $7 \%$ in the heavy EGR strategy.

The above observations are consistent with the general trends of NVO application and serve as a good guide for illustrating the potential of the NVO fuel injection measure.

\subsection{Effects of NVO direct injection on low-load combustion}

This subsection investigates the high-level effects of diesel injection during NVO period on RCCI combustion. The aim is to identify the operating points in which these effects can support efficiency improvement at low engineloads. First, the results of the diesel split ratio (MSR) variation for early and late NVO injection are discussed for both RCCI strategies (EGR and lean). This is followed by details of the effects of injection timing $\left(\mathrm{SOI}_{1}\right)$.

\subsubsection{NVO split ratio variation}

Figures 12 and 13 present the effects of changing the diesel mass split ratio (MSR) for the two low-load RCCI strategies: the heavy EGR (Case A) and the lean concept (Case B) respectively. The MSR is varied from 0 to $50 \%$ of diesel being injected during $\mathrm{NVO}$ and the results are shown for selected NVO injection timings: - $38 \mathrm{CA},-20 \mathrm{CA}$ and 5 CA bTDC. Subsequent plots in Figs. 12 and 13 present selected combustion indicators (CA50, combustion efficiency) and emission indices $\left(\mathrm{NO}_{\mathrm{X}}, \mathrm{CH}_{4}\right)$. The final plot in the two figures depicts a chosen change in IVC temperature, representing mixture thermal state and resulting from NVO fuel injection.
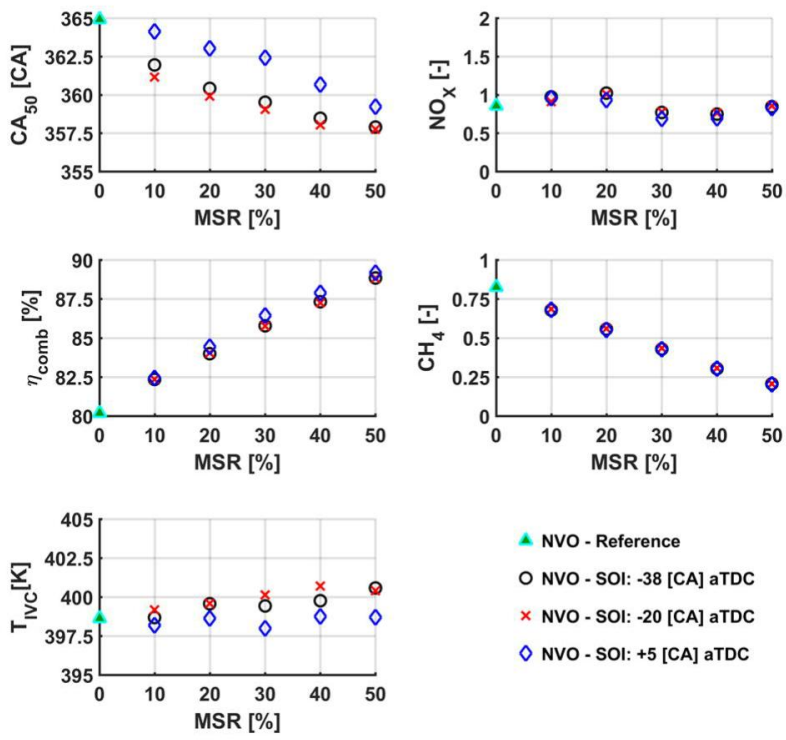

Fig. 12. Varying the split ratio of diesel for selected NVO injection angles. Heavy EGR strategy (Case A). Emissions are given as relative values with respect to the baseline without NVO.

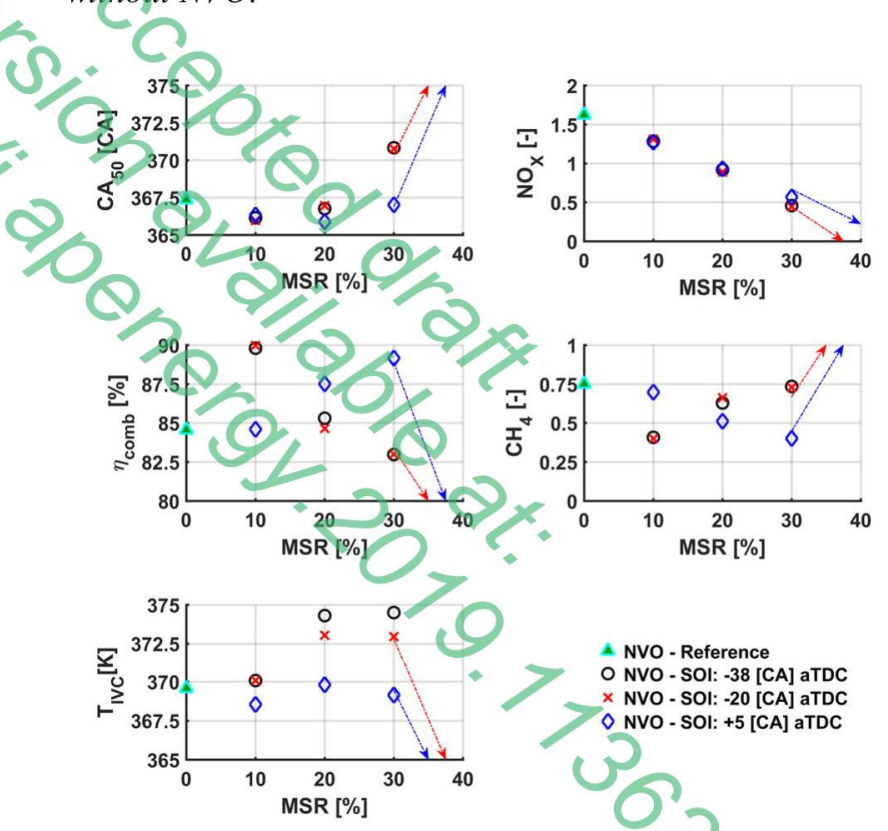

Fig. 13. Varying the split ratio of diesel for selected NVO injection angles. Lean strategy (Case B). Emissions are given as relative values with respect to the baseline without N NVO.

Figure 12 relates to the heavy EGR strategy (Case A) and shows that increasing the MSR has a clear advancing effect on CA50. The most significant effects are observed for injections located in the middle of the NVO window ( -20 $\mathrm{CA}$ ), where the CA50 was reduced from $5 \mathrm{CA}$ (at $\mathrm{MSR}=0$ ) to $-3 \mathrm{CA}$ (for MSR $=50 \%$ ). Changing MSR has least effect on combustion phasing for late NVO injections. It should be noted that the changes in CA 50 locations result solely from changes in combustion duration: changing MSR has almost no effect on start of combustion. Note that there are some thermal effects of NVO fuel injection for SOIs of -20 CA and 
$-38 \mathrm{CA}$. The mixture at IVC gets somewhat hotter at a higher MSR for those injection angles, though the absolute increase in $\mathrm{T}_{\text {IVC }}$ does not exceed $3 \mathrm{~K}$. Nevertheless, such increase alone is known to cause noticeably accelerated combustion in RCCI. In this particular case the trend is diminished by the increase in local diesel concentrations (caused by less diesel being injected during the main event). This is known to have a strong retarding effect on the start of combustion and combustion phasing. The fact that, in the end, the combustion is not retarded may indicate the existence of additional chemical effects of fuel reforming during early NVO injections.

Results of $\mathrm{CH}_{4}$ concentrations for the discussed MSR sweep, shown in Fig. 12, suggest that combustion efficiency is significantly improved when more diesel is injected during NVO. Injecting $50 \%$ of total diesel pilot amount during NVO cuts $\mathrm{CH}_{4}$ emissions by around $80 \%$ compared with the baseline case A. Roughly $18 \%$ is attributed to the thermal effects of applying NVO and the remaining $62 \%$ comes from the pilot fuel injection during NVO. Taking into account corresponding improvements in other $\mathrm{THC}$ and $\mathrm{CO}$ emissions, this in total amounts to an increase of approximately $10 \%$ in combustion efficiency) (Eq. 3 ). Interestingly, despite the fact that the NVO SOI showed a significant impact on combustion phasing, its potential to reduce $\mathrm{CH}_{4}$ remained negligible.

Assuming that the SOI $=5 \mathrm{CA}$ case represents a situation when hardly any reforming may occur, the results suggest that the improvement in combustion efficiency with the Case A strategy (heavy EGR), comes mainly from increased diesel homogenization, improving oxygen entrainment and thus supporting complete combustion. The presence of combustion promoting species introduced to the main event via reformed internal EGR is likely to be less beneficial. However, the latter effect, together with the discussed thermal effects of NVO fuel injection, enables greater mixture homogenization while keeping the combustion phasing close to its optimum. That is beneficial in terms of indicated efficiency and assures more complete oxidation by avoiding extensive quenching of combustion during expansion. $\mathrm{NO}_{\mathrm{X}}$ is not heavily influenced by the NVO injection strategy, with simulated $\mathrm{NO}_{\mathrm{X}}$ concentrations oscillating around the ultra-low values of 1 to $4 \mathrm{ppm}$.

Figure 13 presents high-level results of the MSR sweep performed for the lean RCCI concept (Case B), without external EGR. It is apparent that the trends in combustion and emissions indicators are fundamentally different from the ones recorded for the heavy EGR strategy (Case A). First, stable combustion can no longer be maintained when MSR exceeds 30\%, for all investigated SOIs. (The plots in Fig. 13 are limited to this range in order to keep the y-axis scaling in the region of interest). Beyond $30 \% \mathrm{MSR}$, the mixture introduced to the combustion chamber during the main event gets too homogenized and the local, high-reactivity fuel concentrations are too low to autoignite.

Secondly, for the lean RCCI concept, changing NVO SOI produces major qualitative differences in the observed trends. For late NVO injections, the trend in combustion efficiency improving with greater MSR is monotonic and has a linear characteristic, like the heavy EGR case. This is because the same mechanism related to improved access to oxygen in the fuel-rich zones works in both cases. Improved homogenization (until reaching the strict misfire limit at around 35\% MSR) is possible with elevated IVC temperatures resulting from applying the NVO strategy. Also, in both heavy EGR and lean RCCI cases, moving more mass of diesel fuel from the main injection to $\mathrm{NVO}$ with late SOI timings, has no significant effect on $\mathrm{T}_{\text {IVC. }}$.

The thermal effects observed in terms of IVC temperature in Fig. 13 are qualitatively similar to those discussed in Fig. 12 for the SOI timings of -20 CA and -38 CA. However, the impact of MSR increase on combustion efficiency and phasing for early injection timings is different for the lean strategy. Figure 13 shows that for such cases combustion efficiency improves rapidly for relatively small split ratios, resulting in overall $60 \%$ reduction in $\mathrm{CH}_{4}$ content compared to the base case (without NVO). The combustion efficiency deteriorates when MSR is increased to $20 \%$, and follows that downward trend until the complete misfire limit at around $35 \%$ of diesel injected during NVO. The discrepancy between the trends in IVC temperature and combustion efficiency observed in Fig. 13. suggests composition-related effects manifesting in fuel reforming. Note that in the lean concept, oxygen availability in the exhaust gasses recompressed during the NVO period is much larger than in the heavy EGR case. This argument supports the thesis that NVO injection exerts chemistry-related effects of fuel reforming that are highly dependent on mixture strength. This will be further investigated in Subsection 4.5.

In terms of combustion phasing, the CA50 exhibits almost no sensitivity to the change of MSR for late injections, as shown in Fig. 13. For the early SOIs however, after a small reduction at an MSR of $10 \%$, the CA50 increases significantly for larger MSRs. It should be noted that this CA50 trend is not correlated with one for CA10, which is clearly monotonic and consistent for all SOIs. The CA10 timing adyances with increasing MSR. Both $\mathrm{NO}_{\mathrm{X}}$ concentrations and specific emissions decrease linearly with MSR, and this decrease is independent of SOI timing. Note, however, that in this case the introduction of NVO increased $\mathrm{NO}_{\mathrm{X}}$ emissions by more than $50 \%$. As a result, for the most efficient case of $\mathrm{MSR}=10 \%$, exhaust $\mathrm{NO}_{\mathrm{X}}$ concentrations are $10 \mathrm{ppm}$ higher than the baseline without NVO. In terms of specific emissions, however, this NOx increase is completely compensated by the increase in net indicated efficiency, up from $34 \%$ baseline to almost $36 \%$ at $\mathrm{NVO}$ with $10 \% \mathrm{MSR}$ and $\mathrm{SOI}=-20 \mathrm{CA}$.

\subsubsection{NVO injection timing sweep}

The above discussion revealed that the effects of NVO direct injection on RCCI combustion depend on the SOI during the NVO period and mixture strength. The biggest differences are observed for relatively small MSRs. Figure 14 gives more detail, showing a comparison of both investigated RCCI strategies for variable injection timings and $20 \%$ of diesel injected into the recompressed exhaust gasses. Mixture strength does not vary significantly with SOI and thus is not included in Fig. 14. The corresponding values of $\lambda$ oscillated around 1.7 and 2.9 for the heavy EGR and lean RCCI operation, respectively. 

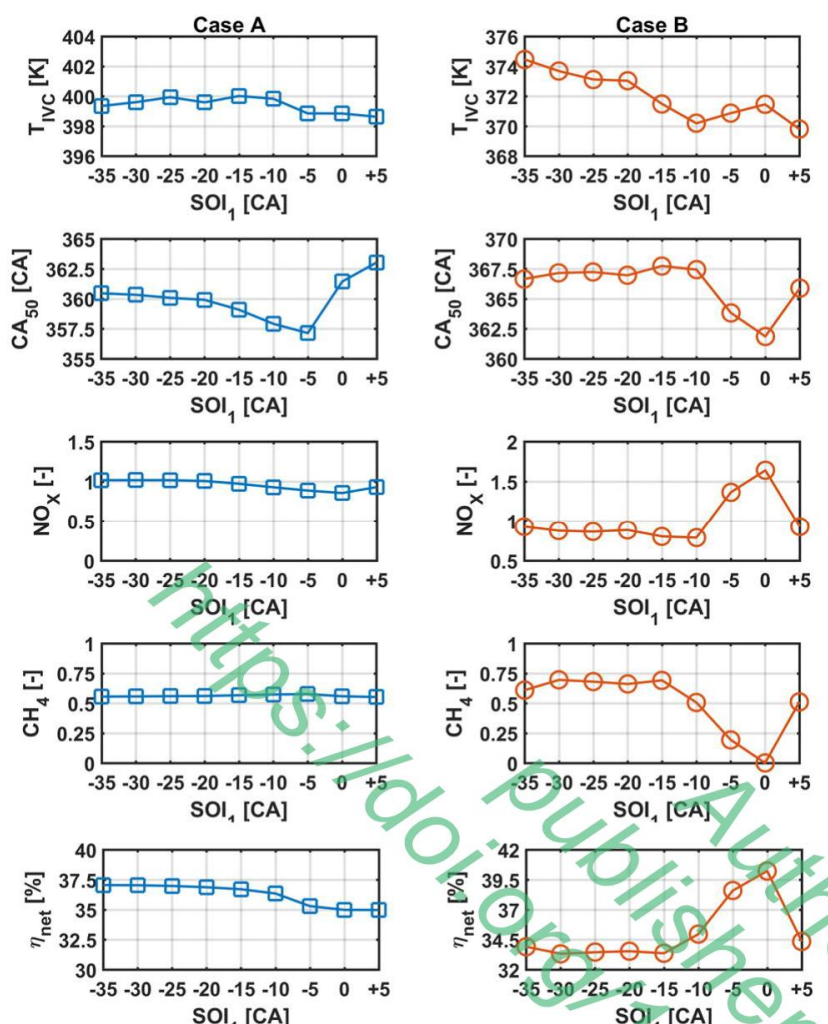

$\mathrm{SOI}_{1}[\mathrm{CA}]$

Figure 14. NVO injection timing sweep for MSR of $20 \%$ performed for: heavy EGR RCCI strategy with $\lambda=1.7$ (Case $A$ - left) and lean strategy with $\lambda=2.9$ (Case $B$-right). Emissions are given as relative values with respect to the base case (without NVO).

The IVC temperature is an important parameter influencing RCCI combustion phasing and efficiency. Figure 14 shows that varying the NVO injection for the heavy EGR strategy does not cause significant changes in the thermal state of the mixture during the main event. For the lean case, on the other hand, the IVC temperature is clearly reduced if the fuel is injected later during NVO. A momentary, slight increase around NVO TDC correlates with significantly increasing combustion efficiency, which produces hotter internal EGR.

Interestingly, the changes in combustion phasing do not clearly follow the trends in IVC temperature. Only CA50 is shown in Fig. 14 because in both investigated cases CA10 and CA50 factors follow almost the same trends. For cases A and $\mathrm{B}, \mathrm{CA} 50$ shows no sensitivity to early SOIs, below -15 CA. Starting from this point, retarding the NVO injection results in a significantly reduced ignition delay in the main event, translating into correspondingly reduced values of the CA50. The combustion is the earliest for SOIs -5 CA and 0 CA for both heavy EGR and lean cases. The trend changes after this point, and the start of combustion gets retarded to reach approximately the same point for $\mathrm{SOI}=5 \mathrm{CA}$ as for the earliest injection timings.

In terms of combustion efficiency, SOI has almost no effect on $\mathrm{CH}_{4}$ content in the heavy EGR strategy (Case A). This supports the thesis made while discussing Fig. 12 that for Case A the efficiency improvement potential of the diesel injection split relates mainly to the increased mixture homogeneity, combined with the elevated base-NVO temperature. This effect is trivial and can be equally well achieved with simpler measures, including reduction of gasdiesel BR, once IVC temperature is sufficiently elevated (by NVO in this case) for auto-ignition of less reactive mixture.

The lean case (Case B), on the other hand, shows considerable potential for combustion efficiency improvement when pilot injection is applied around NVO TDC. At these conditions, $\mathrm{CH}_{4}$ slip is almost completely eliminated, thus providing evidence that NVO injection is a feasible solution for solving RCCI's low-load emissions shortcomings. The combustion efficiency at the best efficiency point in Fig. 14 is over $15 \%$ better than at the baseline lean RCCI point without NVO. But net indicated efficiency shows far less improvement, due to losses associated with NVO (pumping and partial fuel oxidation). Nevertheless, the net efficiency of almost $41 \%$ demonstrated in Fig. 14 compares very favorably with the $34 \%$ of the baseline lean case without NVO, shown in Fig. 11. With the additional benefit of negligible $\mathrm{CH}_{4}$ emissions, this is a cutting-edge result for low-load NG-diesel RCCI. Furthermore, additional optimization can be achieved with NVO window shaping and NVO oxidation phasing.

The $\mathrm{NO}_{\mathrm{x}}$ concentrations plot for the high-EGR case (Case A) shows around 15\% relative decrease with SOI delay. However, since the reference levels of engine-out $\mathrm{NO}_{\mathrm{X}}$ for the high-EGR case with NVO were already ultra-low, the absolute change does not exceed $1 \mathrm{ppm}$ and is considered insignificant. For the lean case (Case B), the combustion efficiency improvement for SOI around NVO TDC is accompaned by an increase of approximately $70 \%$ in $\mathrm{NO}_{\mathrm{X}}$ concentration (up to $40 \mathrm{ppm}$ ). This is understandable because the fuel is burned more completely, raising in-cylinder temperatures and so generating more $\mathrm{NO}_{\mathrm{X}}$. However, specific Nax emissions do not increase significantly (less than $10 \%$ for the discussed NVO SOI point with respect to the baseline lean R(CI) due to the increase in indicated efficiency, and are still below Euro VI limits.

\subsection{Remarks on thermal effects associated with NVO direct injection}

An analysis of the cumulative heat release (CHR) during the NVO period helps explain the trends observed in the previous section, from the perspective of mixture thermal state. The CHR plots for the selected SOI timings for both the heavy EGR and lean RCCI strategies are included in Figs. 15 and 16 , respectively. 


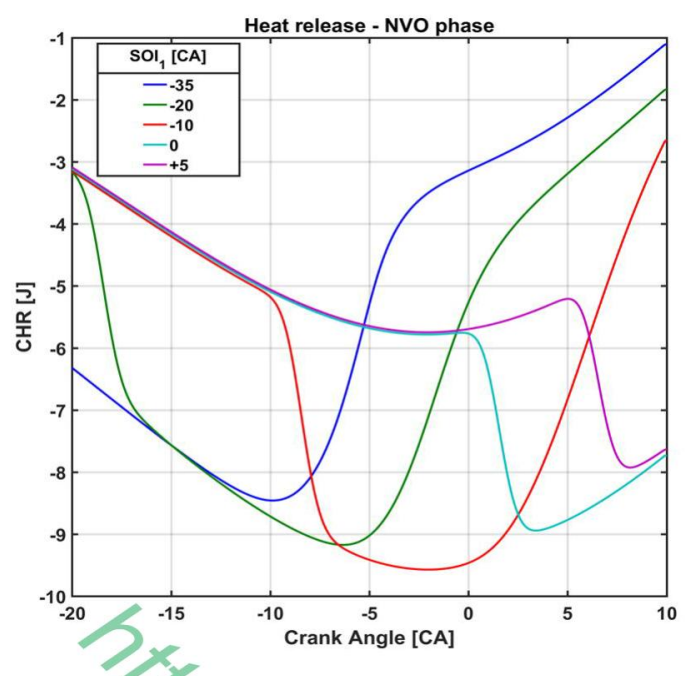

Figure 15. NVO-CHR for selected SOI points of the MSR 20 $\%$ case performed for the heavy EGR RCCI strategy (Case A).

One can note that with heavy EGR (Case A) the heat released for the early SOIs is very small, which hardly compensates for the heat removed from the system due to fuel evaporation and wall transfer. For the entire $\mathrm{SOI}_{1}$ sweep window, the final energy cumulated in the NVO period is almost the same and clearly limited by oxygen availability in the recompressed exhaust gasses. Note however, that some cooling effects are present for late NVO injections (Fig. 15). The above remarks explain the insensitivity of the IVC temperature to early SOI, and only a small decrease in temperature for SOIs around TDC, observed in Fig. 14. Thus, the heavy EGR case is not discussed in detail here and further insight is provided on the basis of the lean conditions (Case B).

Figure 16 shows significantly higher NVO CHR values for the lean case compared to the previously discussed heavy FGR RCCI. A higher global $\lambda$ enables oxidation of a significant portion of fuel during the NVO phase, provided that SOI is sufficiently early to allow the diesel to premix and ignite. The start of NVO oxidation follows a monotonic trend with SOI: the earlier the injection, the earlier the exothermal processes commence. Heat release is evidently constrained by the short expansion process during NVO, suggesting that the changing IVO, together with SOI, could be used to control the in-cylinder reforming process.

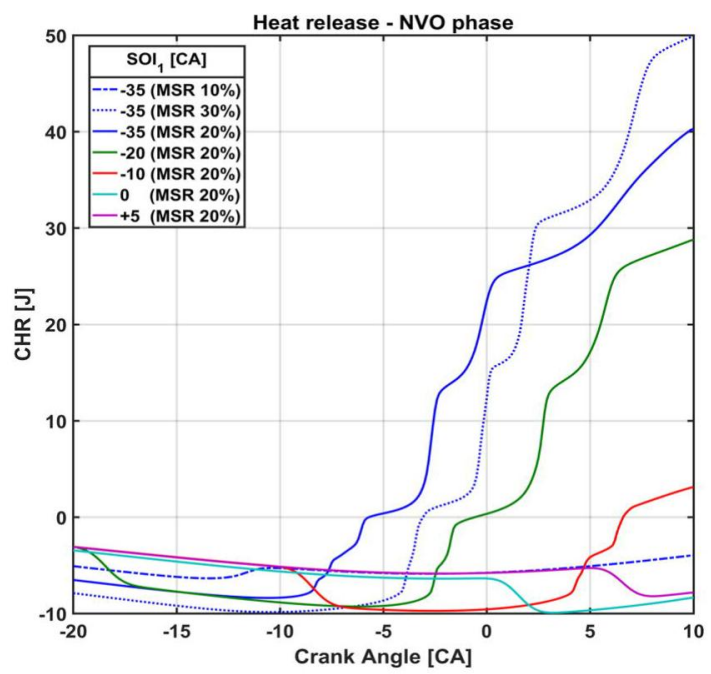

Figure 16. NVO-CHR for selected points of the SOI sweep for the lean RCCI strategy (Case B). For the SOI of -35 CA; the effect of split ratio on CHR is highlighted.

Note that increasing the MSR from $20 \%$ to $30 \%$ does not have significant effect on the amount of heat released during NVO. This explains the lack of change in IVC temperature between these two points (Fig. 13). This is caused by local oxygen concentrations limiting the oxidation processes. However, for MSR 30\% the fuel mixture is too rich, so ignites significantly later than with the $20 \%$ split ratio. If the quantity of diesel injected to NVO is too small (MSR = $10 \%$ ) the oxidation process does not initiate, regardless of NVO injection timings.

The clear trend of increasing heat generated during NVO with retarded SOIs, seen for the lean case with $20 \%$ MSR (Fig, 16), correlates with decreasing NVO temperatures visible in Fig. 17. Here the plotting window is extended towards the intake process in order to provide the link with the IVC conditions presented in Fig. 13.

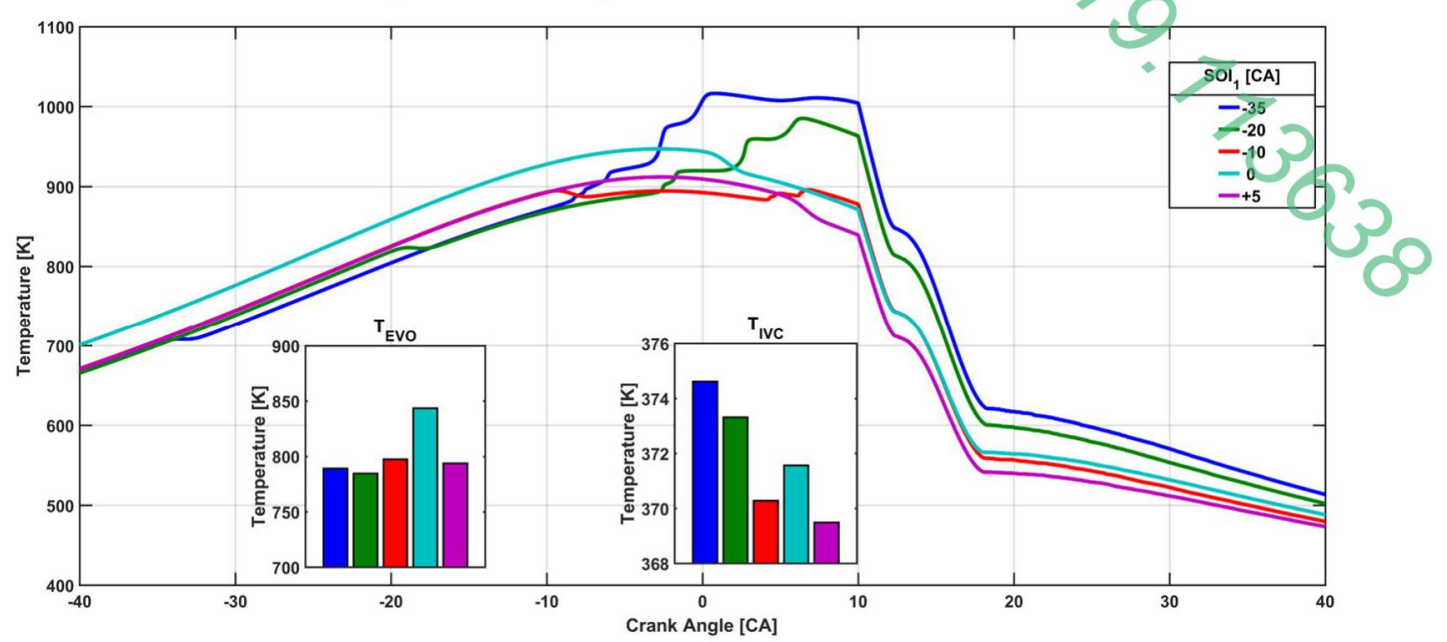

Figure 17. In-cylinder temperature histories during the NVO (left) and intake (right) phase respectively. The lean RCCI strategy (Case B), MSR $=20 \%$, selected NVO injection timings

Note that in terms of the IVC temperature, the trend collapses at SOI at TDC (Fig.16). This results from a significantly 
higher exhaust temperature at this point (see EVO temperature in Fig. 17), caused by its outstanding combustion efficiency. As mentioned before in Subsection 4.3, this elevated efficiency is caused by phenomena of a chemical nature rather than by thermal effects. This is now confirmed with the temperature histories presented in Fig. 17.

The discussion on thermal effects is summarized in

Fig. 18, where the relative increase in the NVO temperature (from EVC to IVO) is assessed together with cumulative heat released at the end of NVO. The residual mass fraction (RMF) at IVC is also presented.
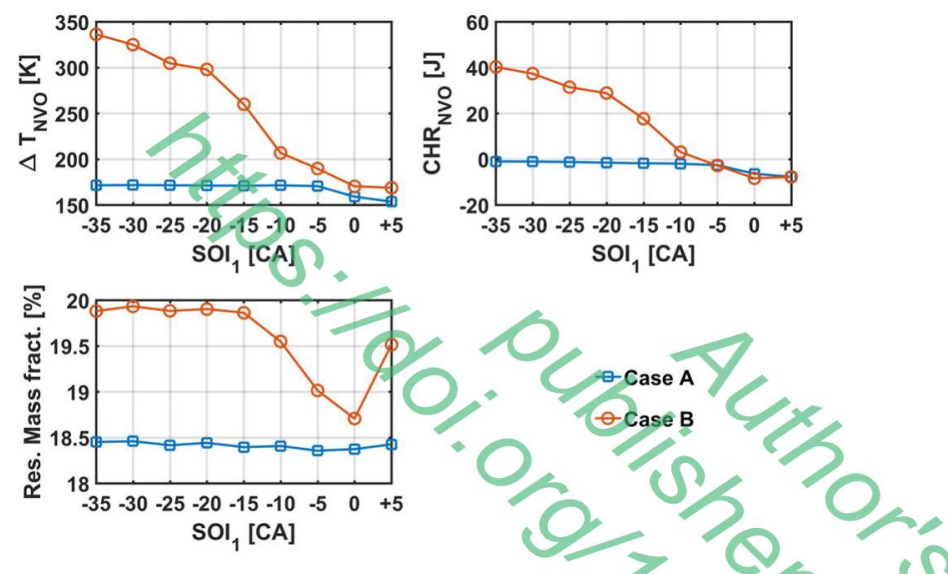

Figure 18. SOI-dependent increase in NVO temperature (from EVC to IVO), CHR at IVO and residual mass fraction at IVC. MSR of $20 \%$, heavy EGR strategy (Case A) and lean strategy (Case B), respectively.

For the lean case, the increase in CHR during NVO with SOI advance increases the gas temperature accordingly, as shown in Fig. 18. Apparently, heat release during NVO determines IVO temperature and pressure. It should be noted that the investigated NVO strategy is associated with high early backflows. Temperature increase intensifies backflows and diminishes fresh-air aspiration. Thus, the higher the IVO temperature derived from heat release, the lower the amount of aspirated air. The trend of rising exhaust temperature produces an additional thermal effect. For SOIs retarded from -15 CA to TDC the exhaust temperature increases by 40 $\mathrm{K}$, which reduces the mass of trapped residuals due to their lower density. Consequently, delaying SOI towards TDC decreases RMF for two reasons: the effect of exhaust temperature on the mass of trapped residuals and the effect of IVO conditions at the intake process. Further delay of SOI increases RMF despite the low thermal effect of fuel injection because at these conditions one can observe a drop in exhaust temperature that favors the amount of trapped residuals.

A similar, yet much weaker, trend in RMF can be observed for heavy EGR (Case A), shown in Fig. 18. Considering that the exhaust temperature is almost at the same level for this SOI sweep, RMF could be determined solely by the thermal effects of fuel injection. For early injections, all parameters shown in Fig. 18 are constant, because the balance between the heat for fuel vaporization and heat release remains the same, as in Fig. 15. But for late SOIs the only heat consumption is for fuel phase change. The possible heat release following fuel vaporization is inhibited by the dropping temperature after IVO. Thus, a drop in temperature and associated improvement in fresh-air aspiration are observed.

\subsection{Remarks on chemical effects associated with RCCI with NVO direct injection}

The previous subsection's discussion allows the conclusion that the efficiency improvement potential of the investigated strategy can be fully exploited when using a high excess air ratio. At such points, the recompressed exhaust gases contain sufficient oxygen to allow fuel reforming to take place. Accordingly, discussion of those effects is narrowed to the lean RCCI strategy.

Figure 19 provides further insight into the diesel reformation/oxidation process at different injection timings. It traces the concentration of $n$-heptane (as diesel surrogate) at both the end of the NVO period (IVO) and the beginning of the main cycle (IVC). For consistency, the same plot is included for methane as a low-reactivity fuel for RCCI.
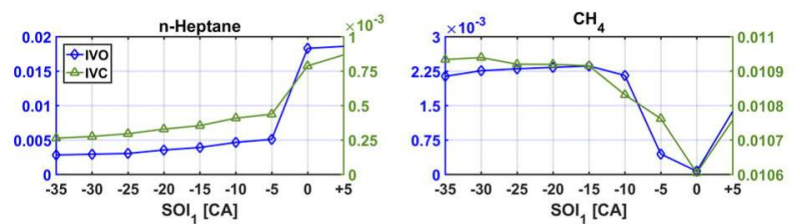

Figure 19. In-cylinder mass fractions of PRFs (n-heptane and $\mathrm{CH}_{4}$ ) at IVO and IVC, at different $\mathrm{NVO}$ injection timings; lean RCCI strategy (Case B), MSR $=20 \%$.

At IVO, n-heptane concentration is roughly four times higher at late injection timings than at early injection timings. In terms of mass, this translates to $75 \% \mathrm{n}$-heptane conversion for the earliest SOI ( $-35 \mathrm{CA})$. Results for the SOI of $+5 \mathrm{CA}$ show hardly any conversion, which is in line with the observation made earlier on the basis of CHR analysis (Fig. 15 and Fig. 16). The $n$-heptane, therefore, is transferred to the main cycle, seen on the IVC plot. However, the concentrations are highly diluted due to the admitted air/gas mixture. Despite fuel conversion, the concentration of n-heptane at the IVC event is to some extent influenced by the amounts of air and trapped residuals. This effect is demonstrated in Fig. 18 as the RMF dependence on SOI: it stems from thermal effects of NVO fuel injection.

The lean RCCI strategy with NVO fuel injection at TDC shows superior combustion efficiency (Fig. 14). This can also be seen in Fig. 19, where the $\mathrm{CH}_{4}$ concentration at IVO is the result of incomplete combustion in the previous cycle. At this point, the $n$-heptane conversion rate is around $5 \%$ of initially injected fuel at NVO TDC As indicated before, the thermal effects alone cannot justify the efficiency increase. In an attempt to explain this phenomena, selected species known to have strong combustion-promoting effects are analyzed in more detail.

One such group of molecules shown to be highly influential for auto-ignition is alkynes. These are compounds generally containing at least one carbon-carbon (C-C) triple bond [54]. From this group, only acetylene $\left(\mathrm{C}_{2} \mathrm{H}_{2}\right)$ is available in the adopted kinetic mechanism. The electronic structure of $\mathrm{C}_{2} \mathrm{H}_{2}$ includes highly excited carbon-hydrogen $(\mathrm{C}-\mathrm{H})$ bonds that have three electrons with unpaired spin on each of the carbon atoms [55]. Therefore, despite the strong C-C triple bond, alkynes such as $\mathrm{C}_{2} \mathrm{H}_{2}$ are very reactive and their 
presence in the cylinder can support combustion efficiency in LTC concepts [56], particularly since the combustion process involves reactions with nucleophiles such as the $\mathrm{OH}^{-i o n s .}$ Following the decreasing reactivity, alkenes (represented by ethylene here) and alkanes (ethane and propane are available in the adopted kinetic mechanism) were commonly reported by various researchers to be relevant from the perspective of kinetically controlled combustion engine concepts [41], [57]. All the above species were demonstrated to be present in NVO reformation products of gasoline and were observed to be stable enough to be transferred to the main combustion cycle [41]. Since the RCCI concept discussed here relies on NVO reformation of diesel instead of gasoline, the intermediate products of $n$-heptane kinetic pathway are also included in the analysis (see Table B1 - Appendix B for nheptane ignition reaction steps). The initiation reactions of $n-$ heptane with $\mathrm{O}$ or $\mathrm{OH}$ radicals result in the formation of these intermediate products, some of which undergo further decomposition to produce heptyl ketohydroperoxide $\left(\mathrm{OC}_{7} \mathrm{H}_{13} \mathrm{O}_{2} \mathrm{H}\right)$ along with additional $\mathrm{OH}$ radicals, as determined by Bentaleb et al, [58]. The authors of [58] also observed that these n-heptane by-products (addressed in this current research as alkyl (heptyl) radicals) are efficient combustion chain propagators and also highly influential in triggering main combustion. Table 4 summarizes the species selected from the chosen reaction mechanism for analysis.

Table 4: Combustion-promoting sub-products of fuel reforming included in the analysis.

\begin{tabular}{|c|c|c|}
\hline \multirow{2}{*}{$\begin{array}{c}\text { Functional } \\
\text { Group }\end{array}$} & \multicolumn{2}{|c|}{ Species } \\
\hline & Name & Formula \\
\hline Alkyne & Acetylene & $\mathrm{C}_{2} \mathrm{H}_{2}$ \\
\hline Alkene & Ethylene & $\mathrm{C}_{2} \mathrm{H}_{4}$ \\
\hline \multirow{2}{*}{ Alkanes* } & Ethane & $\mathrm{C}_{2} \mathrm{H}_{6}$ \\
\hline & Propane & $\mathrm{C}_{3} \mathrm{H}_{8}$ \\
\hline \multirow{6}{*}{$\begin{array}{l}\text { Alkyl } \\
\text { (Heptyl) } \\
\text { radicals }\end{array}$} & 1-Heptyl radical & $\mathrm{C}_{7} \mathrm{H}_{15-1}$ \\
\hline & 2-Heptyl radical & $\mathrm{C}_{7} \mathrm{H}_{15}-2$ \\
\hline & $\begin{array}{l}\text { Hydroperoxy } \\
\text { heptyl radical }\end{array}$ & $\mathrm{C}_{7} \mathrm{II}_{14} \mathrm{O}_{2} \mathrm{II}$ \\
\hline & Heptyl peroxide & $\mathrm{C}_{7} \mathrm{H}_{15} \mathrm{O}_{2}$ \\
\hline & $\begin{array}{l}\text { Hydroperoxy } \\
\text { heptylperoxy } \\
\text { radical }\end{array}$ & $\mathrm{O}_{2} \mathrm{C}_{7} \mathrm{H}_{14} \mathrm{O}_{2} \mathrm{H}$ \\
\hline & $\begin{array}{l}\text { Heptyl } \\
\text { ketoperoxide }\end{array}$ & $\mathrm{OC}_{7} \mathrm{H}_{13} \mathrm{O}_{2} \mathrm{H}$ \\
\hline
\end{tabular}

All the intermediate combustion sub-products, listed in Table 4, are continually generated along the diesel (n-heptane) oxidation pathway during the NVO phase, while also being mostly consumed along the process. Substantial amounts of those species can survive and be transferred to the main combustion phase, but only if the kinetic chain is interrupted, for example by combustion quenching or lack of oxidizer. As this process is not the focus of this study, the evolution traces are omitted in favor of showing the net effect, that is - the concentrations at the end of NVO period and beginning of the main cycle, as done for $n$-heptane and $\mathrm{CH}_{4}$ in Fig. 19. So, Fig 20 shows the concentrations for the four above-mentioned reactivity-enhancing sub-products of $n$-heptane reformation at IVO and IVC.
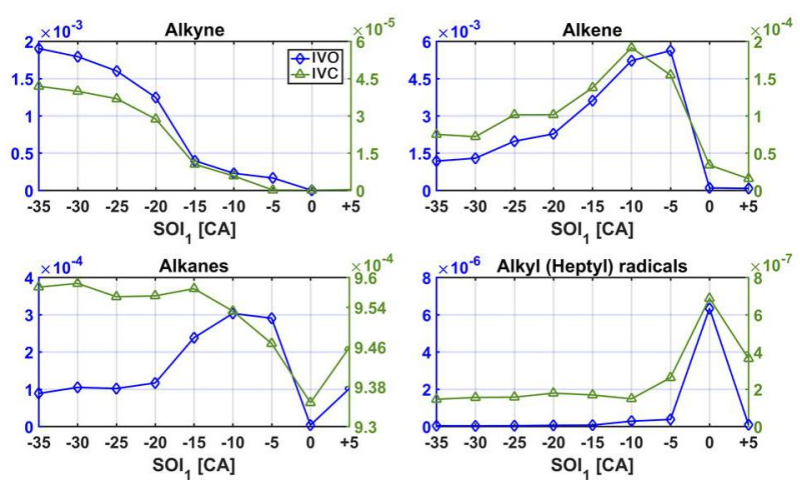

Fig. 20. In-cylinder mass fractions of Alkynes $\left(\mathrm{C}_{2} \mathrm{H}_{2}\right)$, alkenes $\left(\mathrm{C}_{2} \mathrm{H}_{4}\right)$, alkanes $\left(\mathrm{C}_{2} \mathrm{H}_{6}, \mathrm{C}_{3} \mathrm{H}_{8}\right)$ and Alkyl (Heptyl) radicals at IVO and IVC, at different NVO injection timings; lean RCCI strategy (Case B), $M S R=20 \%$.

One can see that significant amounts of alkynes and alkanes are present in the reformed gasses. Alkynes are mainly generated with early injection timings where, as observed in Fig. 19, the n-heptane conversion rates are the highest. As discussed in Section 4.4, the reforming process is limited in early injection timings by local oxygen availability: these conditions apparently support alkyne production. Alkanes, on the other hand, are produced most extensively in the midrange of explored SOI angles, where n-heptane conversion is constrained by rapid reduction of in-cylinder temperatures, associated with opening the intake valve. The generation of alkanes follows the same trend, yet the resulting concentrations are one order of magnitude lower. Summarizing, for the explored NVO SOI angles from -35 to $-10 \mathrm{CA}$ a substantial generation of auto-ignition-promoting species is observed, yet their effect on final combustion efficiency seems diminished by a reduced amount of highreactivity diesel that is consumed to generate heat during NVO. Thus, the net effect of mixture reactivity change and IVC temperature increase on combustion efficiency is almost non-existent for early SOIs.

An analysis of reactive species produced at NVO injections close to the TDC shows completely different trends. It is evident from Fig. 20 that all of the mentioned species produced in significant amounts during the early NVO injections are not present for SOI at TDC. On the other hand, the alkyl (heptyl) radicals clearly peak at this SOI point. This is apparently attributable to the fact that the n-heptane reforming is initiated at around $5 \mathrm{CA}$, yet is almost immediately broken by the IVO-related temperature discharge. Note that the discussed heptyl radicals are the only species for which the end-NVO mass/concentration is evidently higher for SOI at TDC than at other injection timings. Ultimately, the observed superior combustion efficiency at SOI of $0 \mathrm{CA}$ can be attributed to enhanced mixture reactivity caused by the re-introduction of those species to the main event, together with the unreformed, residual n-heptane. In other words, compared to the base case without NVO, one can observe a particular combination of the following three effects. First, IVC temperature is elevated by NVO thermal effects. Second, there is better reactivity (nheptane is consumed in NVO to a minor extent, but highly reactive intermediate species are created). Lastly, there is better mixture homogenization (while keeping similar BR the reintroduced NVO n-heptane is distributed homogenously, 
contrary to the direct injected fuel value which is ultimately reduced by $20 \%$ ).

\subsection{Discussion and outlook on applicability}

Hitherto the results of both the NVO-SOI $\left(\mathrm{SOI}_{1}\right)$ and MSR variations have been investigated separately, followed by analysis of the thermal and chemical effects of fuel reforming at two different lambda/EGR scenarios. The aim of this subsection is to provide a coherent view of the direct NVO injected RCCI engine concept. The individual observations are therefore summarized to give a general explanation of the results achieved. This is followed by a brief outlook on how to apply the results in practice, including conditions that have to be met to make this feasible.

\subsubsection{Discussion}

This study has investigated two competing strategies to realize efficient low-load RCCI: an uncooled exhaust gas recirculation strategy and a lean burn concept without EGR. The heavy EGR strategy combined with heavy intake pressure-boosting has some advantages over the lean strategy, in terms of both indicated efficiency and lower $\mathrm{CH}_{4}$ emissions when the NVO strategy is not applied. Also, hot EGR supports a higher IVC temperature, which is traditionally the main factor behind improved combustion efficiency. In both strategies, applying NVO allows further IVC temperature increase by substantial internal EGR (up to almost 20\%). This, without any optimization on combustion, provides around $15 \%$ reduction in $\mathrm{CH}_{4}$ emissions. More importantly, NVO allows achievement of peak exhaust recompression temperatures above $850 \mathrm{~K}$, high enough to trigger diesel reforming/oxidation reactions. However, this is at the expense of higher pumping losses, which ultimately results in indicated efficiencies lower than the baseline cases. Pumping losses for the EGR case increase from roughly $2.5 \%$ to over $7 \%$ of the total energy share. For the lean case with the same NVO configuration, pumping losses are roughly half that.

Applying diesel injection to the recompressed residuals with the selected NVO configuration produces qualitatively different effects for each of the two strategies. For the heavy EGR strategy, hardly any reactions occur during NVO because the process is severely limited by local oxygen availability in diesel-rich zones (low lambda). The increased IVC temperature, increased homogenization of diesel and possibly slight reactivity enhancement (through the generation of reformed species) all allow combustion efficiency in the main cycle to rise with increasing diesel split ratio and oxygen entrainment. According to the simulation results, moving up to $40 \%$ of diesel fuel to NVO is possible while still mmaintaining the desired combustion phasing. This in total provides around 75\% reduction in exhaust gas $\mathrm{CH}_{4}$ concentrations. At the same time, the higher combustion efficiency compensates for the higher pumping losses. Consequently, the heavy EGR strategy with fuel-injected NVO provides the same net indicated efficiency as that of the baseline (roughly $38 \%$ ). This accounts for indicated specific $\mathrm{CH}_{4}$ emissions of $4.4 \mathrm{~g} / \mathrm{kWh}$.

The lean RCCI strategy can take greater advantage of NVO fuel reforming effects, thanks to higher oxygen availability in the recompressed exhaust gasses. Here, contrary to the EGR strategy, the amount of reformed fuel greatly depends on the time of diesel injection during the recompression phase. This can be used to achieve a balance between complex thermal and chemical effects which generate different amounts of reactivity-enhancing subproducts. The best efficiency results can be expected with relatively small amounts of diesel (split ratio of 20\%) injected around NVO TDC. The simulation results show that, at such conditions, combustion efficiency is almost $99 \%$, with ultralow $\mathrm{CH}_{4}$ emissions (below $0.7 \mathrm{~g} / \mathrm{kWh}$ indicated specific emissions). This is enabled mainly by the transfer of substantial amounts of heptyl radicals to the main combustion event, without sacrificing n-heptane for generating heat at NVO. The superior combustion efficiency, together with faster heat release and good phasing, demonstrate very good indicated net efficiency of $40.5 \%$, despite substantial pumping losses introduced by NVO. Overall, low-load net efficiency is roughly 5.5 percentage points better than for the baseline lean strategy and 3 pp. higher than heavy EGR RCCI without NVO.

\subsubsection{Outlook}

Fully flexible valve trains will become an industrial standard for the next generation of combustion engines [59]. This is especially relevant for RCCI: variable intake valve actuation has already proven to be necessary for load range extension [21], tackling one of the main drawbacks of RCCI engines, VVA technology also opens up new routes towards better efficiency of NG-diesel RCCI, as shown in [21]. Commercial applicability of NG-diesel RCCI hinges on the ability to oyercome its problem of low combustion efficiencies at partial loads. This key issue of concept applicability in the real world underpins and justifies this research into RCCI operated in an NVO-direct injection mode at low loads. Furthermore, multi-injection capability across the full engine-cycle is already a standard feature of commonrail diesel injection systems, so the considered strategy demands no additional hardware investments to the baseline RCCI engine concept.

This study shows that the concept, especially when coupled with ultra-lean engine operation, has potential to solve the methane slip problem of natural gas-based RCCI combustion at low engine-loads. Note that the exploratory nature of the research does not involve combustion cooptimization with other operating parameters like BR, lambda, IVC temperature or main injection timing. Performing such optimization is one of the research topics that should be addressed to fully understand the concept's potential. In particular, it should focus on finding the NVIO configuration that minimizes the excessive pumping losses.

Results of the present work already identify the main challenge for the NVO direct injection strategy. System complexity looks high, entailing design of a sophisticated control algorithm. Additionally, the complex matrix of thermal and chemical interactions discovered in this study shows that the system is highly non-linear and optimization is possible for a narrow window of operating parameters. A model-based control approach needs to be developed and validated, requiring development of control models capable of capturing main sensitivities. The XCCI tool chain used in this work can offer such sensitivity, but model-reduction 
mechanisms are needed for control algorithms capable of working in real-time.

More importantly, note that the present study's model involves a set of simplifying assumptions regarding both the flow field and, to some extent, the reaction kinetics. Although these assumptions have been carefully revised to ensure the feasibility of this work's qualitative investigation of the effects examined, an exact quantification is only possible with properly designed experiments. To this end, it is considered essential that this study's results are confirmed experimentally by fundamental research.

\section{Conclusions}

The present work, by means of numerical simulation, investigates the prospects of RCCI combustion with negative valve overlap fuel reforming. The objective is to explore the potential of improving low- load combustion efficiency, which is a major challenge for natural gas - diesel RCCI systems. The achieved results support the following conclusions:

(i) Negative valve overlap, with early exhaust valve opening and closing, allows attainment of stable RCCI combustion.

(ii) Higher intake valve closing temperatures are achievable, giving around $15 \%$ reduction in methane emissions, but accompanied by reduced efficiency due to pumping losses.

(iii) Exhaust peak recompression temperatures rise above $850 \mathrm{~K}$, sufficient to trigger diesel-reforming reactions,

(iv) The effects on combustion of direct diesel injection during negative valve overlap are heavily dependent on mixture strength.

(v) The heavy exhaust gas recirculation RCCI case shows up to $75 \%$ methane emission reduction is attainable at low load through combined effect of increased mixture homogenization and elevated temperature at intake valve closing.

(vi) Lean RCCI operation with late negative valve overlap injections can take additional advantage of chemical effects of fuel reforming, enabling superior combustion efficiency with methane emissions below Euro VI level.

(vii) This simulation study demonstrates best efficiency at $15 \%$ load of $40.5 \%$, some $3 \mathrm{pp}$ better than current experimental state of the art. There is potential for further improvement with negative valve overlap phasing / blend ratio / diesel injection timing co-optimization.

(viii) The developed strategy is considered applicable on the state-of-the-art dual-fuel gas engines without hardware changes. Closed-loop, multi-input, multi-output combustion control is an enabler.

\section{Acknowledgments}

The authors acknowledge the support of TNO Netherlands, for making the XCCI model available for this study. TNO also provided the experimental data for model validation. To this end, our special thanks go to Martijn Stamm (TNO Powertrains) for granting the permissions and his general support and Ruud Verbeek (TNO STL) for his insightful remarks enabling clear and focused discussion. We also thank David Wilcox for final editing.
Additionally, Jacek Hunicz acknowledges financial support from the National Science Centre of Poland, under the grant No. 2015/17/B/ST8/03279.

References

[1] Reitz RD, Duraisamy G. Review of high efficiency and clean reactivity controlled compression ignition (RCCI) combustion in internal combustion engines. Prog Energy Combust Sci 2015;46:12-71. https://doi.org/10.1016/j.pecs.2014.05.003.

[2] Nieman DE, Dempsey AB, Reitz RD. Heavy-Duty RCCI Operation Using Natural Gas and Diesel. SAE Int J Engines 2012;5:2012-01-0379.

https://doi.org/10.4271/2012-01-0379.

[3] Jia Z, Denbratt I. Experimental Investigation of Natural Gas-Diesel Dual-Fuel RCCI in a HeavyDuty Engine. SAE Int J Engines 2015;8:2015-010838. https://doi.org/10.4271/2015-01-0838.

[4] Dahodwala M, Joshi S, Koehler E, Franke M, Tomazic D. Experimental and Computational Analysis of Diesel-Natural Gas RCCI Combustion in Heavy-Duty Engines., 2015. https://doi.org/10.4271/2015-01-0849.

[5] Doosje E, Willems F, Baert R. Experimental Demonstration of RCCI in Heavy-Duty Engines using Diesel and Natural Gas. SAE Technical Paper 2014-01-1318, 2014. https://doi.org/10.4271/201401-1318.

Splitter D, Wissink M, DelVescovo D, Reitz RD. RCCI Engine Operation Towards 60\% Thermal Efficiency. SAE Technical Paper 2013-01-0279, 2013. https://doi.org/10.4271/2013-01-0279.

[7] Dempsey AB, Walker NR, Gingrich E, Reitz RD. Comparison of Low Temperature Combustion Strategies for Advanced Compression Ignition Engines with a Focus on Controllability. Combust Sci Technol 2014,186:210-41.

https://doi.org/10.1080/00102202.2013.858137.

[8] Splitter D, Wissink M, DelVescovo D, Reitz RD. Improving the Understanding of Intake and Charge Effects for Increasing RCCI Engine Efficiency. SAE Int J Engines 2014;7:2014-01-1325.

https://doi.org/10.4271/2014-01-1325.

[9] Mikulski M, Bekdemir C. Understanding the role of low reactivity fuel stratification in a dual fuel RCCI engine - A simulation study. Appl Energy 2017;191:689-708.

https://doi.org/10.1016/j.apenergy.2017.01.080.

[10] Hanson RM, Kokjohn SL, Splitter DA, Reitz RD. An Experimental Investigation of Fuel Reactivity Controlled PCCI Combustion in a Heavy-Duty Engine. SAE Int J Engines 2010;3:2010-01-0864. https://doi.org/10.4271/2010-01-0864.

[11] Yu C, Wang J, Yu W, Liu J, Gao D. Research on Low Temperature Combustion of Homogeneous Charge Induced Ignition (HCII) in a Light-Duty Diesel Engine. Proceedings of the FISITA 2012 World Automotive Congress, Berlin, Heidelberg: Springer Berlin Heidelberg; 2013, p. 195-204. https://doi.org/10.1007/978-3-642-33841-0_15.

[12] Desantes JM, Benajes J, García A, MonsalveSerrano J. The role of the in-cylinder gas temperature and oxygen concentration over low load reactivity controlled compression ignition combustion efficiency. Energy 2014;78:854-68. 
https://doi.org/10.1016/j.energy.2014.10.080.

[13] Benajes J, Molina S, García A, Monsalve-Serrano J. Effects of direct injection timing and blending ratio on RCCI combustion with different low reactivity fuels. Energy Convers Manag 2015;99:193-209. https://doi.org/10.1016/j.enconman.2015.04.046.

[14] Li J, Yang WM, An H, Zhou DZ, Yu WB, Wang JX, Li L. Numerical investigation on the effect of reactivity gradient in an RCCI engine fueled with gasoline and diesel. Energy Convers Manag 2015;92:342-52.

https://doi.org/10.1016/j.enconman.2014.12.071.

[15] Li K, Wang H, Wei Y, Liu M. Preparation and characterization of $\mathrm{Ce} 1-\mathrm{xFexO} 2$ complex oxides and its catalytic activity for methane selective oxidation. J Rare Earths 2008;26:245-9. https://doi.org/10.1016/S1002-0721(08)60074-5.

[16] Hong H, Parvate-Patil GB, Gordon B. Review and analysis of variable valve timing strategies - eight ways to approach. Proceedings of the Institution of Mechanical Engineers, Part D: Journal of Automobile Engineering 2004;218:1179-200. https://doi.org/10.1177/095440700421801013.

[17] Hunicz J, Kordos P. An experimental study of fuel injection strategies in CAI gasoline engine. Exp Therm Fluid Sci 2011;35:243-52. https://doi.org/10.1016/j.expthermflusci.2010.09.00 7.

[18] Molina S, García A, Pastor JM, Belarte E, Balloul I. Operating range extension of RCCI combustion concept from low to full load in a heavy-duty engine. Appl Energy 2015;143:211-27. https://doi.org/10.1016/j.apenergy.2015.01.035.

[19] Benajes J, Pastor JV, García A, Monsalve-Serrano J. The potential of RCCI concept to meet EURO VI NOx limitation and ultra-low soot emissions in a heavy-duty engine over the whole engine map. Fuel 2015;159:952-61.

https://doi.org/10.1016/j.fuel.2015.07.064.

[20] García-Valladolid P, Tunestål P, Monsalve-Serrano J, García A, Hyvönen J. Impact of diesel pilot distribution on the ignition process of a dual fuel medium speed marine engine. Energy Convers Manag 2017;149:192-205. https://doi.org/10.1016/j.enconman.2017.07.023.

[21] Mikulski M, Balakrishnan PR, Doosje E, Bekdemir C. Variable Valve Actuation Strategies for Better Efficiency Load Range and Thermal Management in an RCCI Engine. SAE Technical Paper 2018-010254, 2018. https://doi.org/10.4271/2018-01-0254.

[22] Xu G, Jia M, Li Y, Chang Y, Wang T. Potential of reactivity controlled compression ignition (RCCI) combustion coupled with variable valve timing (VVT) strategy for meeting Euro 6 emission regulations and high fuel efficiency in a heavy-duty diesel engine. Energy Convers Manag 2018;171:683-98.

https://doi.org/10.1016/j.enconman.2018.06.034.

[23] Bharath AN, Kalva N, Reitz RD, Rutland CJ. Use of Early Exhaust Valve Opening to Improve

Combustion Efficiency and Catalyst Effectiveness in a Multi-Cylinder RCCI Engine System: A Simulation Study. ASME. Internal Combustion Engine Division Fall Technical Conference, Volume 1: Large Bore Engines; Fuels; Advanced
Combustion; Emissions Control Systems ():V001T03A011.

https://doi.org/10.1115/ICEF2014-5534.

[24] Koopmans L, Strömberg E, Denbratt I. The

Influence of PRF and Commercial Fuels with High Octane Number on the Auto-ignition Timing of an Engine Operated in HCCI Combustion Mode with Negative Valve Overlap. SAE Technical Paper 2004-01-1967, 2004. https://doi.org/10.4271/200401-1967.

[25] Hunicz J. An experimental study of negative valve overlap injection effects and their impact on combustion in a gasoline HCCI engine. Fuel 2014;117:236-50.

https://doi.org/10.1016/j.fuel.2013.09.079.

[26] Lavy J, Dabadie J-C, Angelberger C, Duret P, Willand J, Juretzka A, Schäflein J, Ma T, Lendresse Y, Satre A, Schulz C, Krämer H, Zhao H, Damiano L. Innovative Ultra-low NOx Controlled AutoIgnition Combustion Process for Gasoline Engines: the 4-SPACE Project. SAE Technical Paper 200001-1837, 2000. https://doi.org/10.4271/2000-011837.

[27] Kontarakis G, Collings N, Ma T. Demonstration of HCCI Using a Single Cylinder Four-stroke SI Engine with Modified Valve Timing. SAE Technical Paper 2000-01-2870, 2000. https://doi.org/10.4271/2000-01-2870. Koopmans L, Ström H, Lundgren S, Backlund O, Denbratt I. Demonstrating a SI-HCCI-SI Mode Change on a Volvo 5-Cylinder Electronic Valve Control Engine. SAE Technical Paper 2003-010753, 2003. https://doi.org/10.4271/2003-01-0753. Rodriguez JF, Cheng W. Potential of Negative Valve Overlap for Part-Load Efficiency Improvement in Gasoline Engines. SAE Int J Engines 2018;11(6): 657-668. https://doi.org/10.4271/2018-01-0377.

[30] Borgqvist P, Tuner M, Mello A, Tunestal P, Johansson B. The Usefulness of Negative Valve Overlap for Gasoline Partially Premixed Combustion, PPC. SAE Technical Paper 2012-011578, 2012. https://oi.org/10.4271/2012-01-1578.

[31] Urushihara T, Hiraya K, Kakuhou A, Itoh T. Expansion of HCCI Operating Region by the Combination of Direct Fuel Injection, Negative Valve Overlap and Internal Fuel Reformation. SAE Technical Paper 2003-01-0749, 2003. https://doi.org/10.4271/2003-01-0749.

[32] Fitzgerald RP, Steeper R. Thermal and Chemical Effects of NVO Fuel Injection on HCCD Combustion. SAE Int J Engines 2010,3:46-64. hltps:/'doi.org/10.4271/2010-01-0164.

[33] Borgqvist P, Tunestal P, Johansson B. Comparison of Negative Valve Overlap (NVO) and Rebreathing Valve Strategies on a Gasoline PPC Engine at Low Load and Idle Operating Conditions. SAE Int J Engines 2013;6(1): 366-378.

https://doi.org/10.4271/2013-01-0902.

[34] Huelser T, Schulz C, Brands T, Grunefeld G, Koss H-J, Morcinkowski B, Pischinger S, Adomeit P. Probing Species Formed by Pilot Injection During Re-Compression in a Controlled Auto-Ignition Engine by $\mathrm{H}_{2} \mathrm{CO}$ LIF and Chemiluminescence Imaging. SAE Int J Engines 2014; 7(2):772-789. 
https://doi.org/10.4271/2014-01-1275.

[35] Steeper RR, Davisson ML. Analysis of Gasoline Negative-Valve-Overlap Fueling via Dump

Sampling. SAE Int J Engines 2014; 7(2):762-771. https://doi.org/10.4271/2014-01-1273.

[36] Yu W, Xie H, Chen T, Li L, Song K, Zhao H. Effects of Active Species in Residual Gas on AutoIgnition in a HCCI Gasoline Engine, 2012. SAE Technical Paper 2012-01-1115, 2012. https://doi.org/10.4271/2012-01-1115.

[37] Puranam SV, Steeper RR. The Effect of Acetylene on Iso-octane Combustion in an HCCI Engine with NVO. SAE Int J Engines 2012; 5(4):1551-1560. https://oi.org/10.4271/2012-01-1574.

[38] Ekoto IW, Wolk BM, Northrop WF, Hansen N, Moshammer K. Tailoring Charge Reactivity Using In-Cylinder Generated Reformate for Gasoline Compression Ignition Strategies. J Eng Gas Turbines Power 2017;139:122801. https://doi.org/10.1115/1.4037207.

[39] Aroonsrisopon T, Nitz DG, Waldman JO, Foster DE, Iida M. A Computational Analysis of Direct Fuel Injection During the Negative Valve Overlap Period in an Iso-Octane Fueled HCCI Engine. SAF Technical Paper 2007-01-0227, 2007. https://doi.org/10.4271/2007-01-0227.

[40] Waldman J, Nitz D, Aroonsrisopon T, Foster DE, Iida M. Experimental Investigation into the Effects of Direct Fuel Injection During the Negative Valve Overlap Period in an Gasoline Fueled HCCIEngine, SAE International; 2007. doi:10.4271/2007-010219.

[41] Hunicz J, Mikulski M. Investigation of the thermal effects of fuel injection into retained residuals in HCCI engine. Appl Energy 2018;228:1966-84. https://doi.org/10.1016/j.apenergy.2018.07.075.

[42] Kuzuoka K, Kondo T, Kudo H, Taniguchi H, Chishima H, Hashimoto K. Controlling combustion with negative valve overlap in a gasoline-diesel dual-fuel compression ignition engine. Int $\mathbf{J}$ Engine Res 2016;17:354-65.

https://doi.org/10.1177/1468087415580216.

[43] Neshat E, Saray RK, Hosseini V. Effect of reformer gas blending on homogeneous charge compression ignition combustion of primary reference fuels using multi zone model and semi detailed chemical-kinetic mechanism. Appl Energy 2016;179:463-78. https://doi.org/10.1016/j.apenergy.2016.06.150.

[44] Hwang JT, Kane SP, Northrop WF. Demonstration of Single-Fuel Reactivity Controlled Compression Ignition Using Reformed Exhaust Gas Recirculation. SAE Technical Paper 2018-01-0262, 2018. https://doi.org/10.4271/2018-01-0262.

[45] Lin Y, Li X, Twigg MV, Northrop W. Opposedflow heterogeneous reactor for partial oxidation of methane. Fall Technical Meeting of the Western States Section of the Combustion Institute, WSSCI 2017, Laramie, United States.

https://experts.umn.edu/en/publications/opposedflow-heterogeneous-reactor-for-partial-oxidation-ofmetha (accessed February 23, 2018).

[46] Asai G, Watanabe Y, Ishiguro S, Shibata G, Ogawa H, Kobashi Y. Chemical Reaction Processes of Fuel Reformation by Diesel Engine Piston Compression of Rich Homogeneous Air-Fuel Mixture. SAE Int J
Engines 2017;10:2624-35.

https://www.sae.org/publications/technicalpapers/content/2017-32-0120/ (accessed October 15, 2018).

[47] Bekdemir C, Baert R, Willems F, Somers B. Towards Control-Oriented Modeling of Natural Gas-Diesel RCCI Combustion. SAE Technical Paper 2015-01-1745, 2015. https://doi.org/10.4271/2015-01-1745.

[48] Chang J, Güralp O, Filipi Z, Assanis DN, Kuo T-W, Nait P, Rask R. New Heat Transfer Correlation for an HCCI Engine Derived from Measurements of Instantaneous Surface Heat Flux. SAE Technical Paper 2004-01-2996, 2004.

https://doi.org/10.4271/2004-01-2996.

[49] Peters N, Paczko G, Seiser R, Seshadri K.

Temperature cross-over and non-thermal runaway at two-stage ignition of $n$-heptane. Combust Flame 2002;128:38-59. https://doi.org/10.1016/S00102180(01)00331-5.

[50] Smith G.P., Golden, D.M., Frenklach, M, Moriarty NW, Eiteneer B, Goldenberg M, Bowman CT, Hanson RK, Song S, Gardiner WC Jr., Lissianski VV, Qin Z. GRI-MECH 3.02018.

http://www.me.berkeley.edu/gri_mech/ (accessed January 04, 2018).

[51] Mikulski M, Bekdemir C, Willems F. Experimental validation of a combustion kinetics based multi-zone model for natural gas-diesel RCCI engines. Symposium for Combustion Control, Aachen, Germany: 2016.

Heywood JB. Internal Combustion Engine Fundamentals, McGraw-Hill Books, 1988. Ebrahimi K, Koch C. Symmetric Negative Valve Overlap Effects on Energy Distribution of a Single Cylinder HCCI Engine. SAE Technical Paper 201801-1250, 2018. https://doi.org/10.4271/2018-011250.

[54] Schrock RR. Multiple Metal-Carbon Bonds for Catalytic Metathesis Reactions (Nobel Lecture). Angew Chemie Int Ed 2006;45:3748-59. https://doi.org/10.1002/anie.200600085.

[55] Xu LT, Dunning TH. Variations in the Nature of Triple Bonds: The N2, HCN, and HC2H Series. J Phys Chem A 2016;120:4526-33.

https://doi.org/10.1021/acs.jpca.6b03631.

[56] Hunicz J. An experimental study into the chemical effects of direct gasoline injection into retained residuals in a homogeneous charge compression ignition engine. Int J Engine Res 2016; 17:1031-44. https://doi.org/10.1177/1468087416636492.

[57] Fitzgerald RP, Steeper R. Thermal and Chemical Efrects of NVO Fuel Injection on HCCI Combustion. SAE Int J Engines 2010; 3(1):46-64. https://doi.org/10.4271/2010-01-0164.

[58] Bentaleb S, Blin-Simiand N, Jeanney P, Magne L, Moreau N, Pasquiers S, Tardiveau P. Ignition of Lean Air / Hydrocarbon Mixtures at Low Temperature by a Single Corona Discharge Nanosecond Pulse. AerospaceLab, 2015. https://doi.org/10.12762/2015.AL10-09.

[59] ULF ÅSTRAND. Wärtsilä 31. Detail -Wärtsilä Tech J 2015. https://www.wartsila.com/twentyfour7/indetail/the-new-wartsila-31-engine (accessed December 15, 2018). 


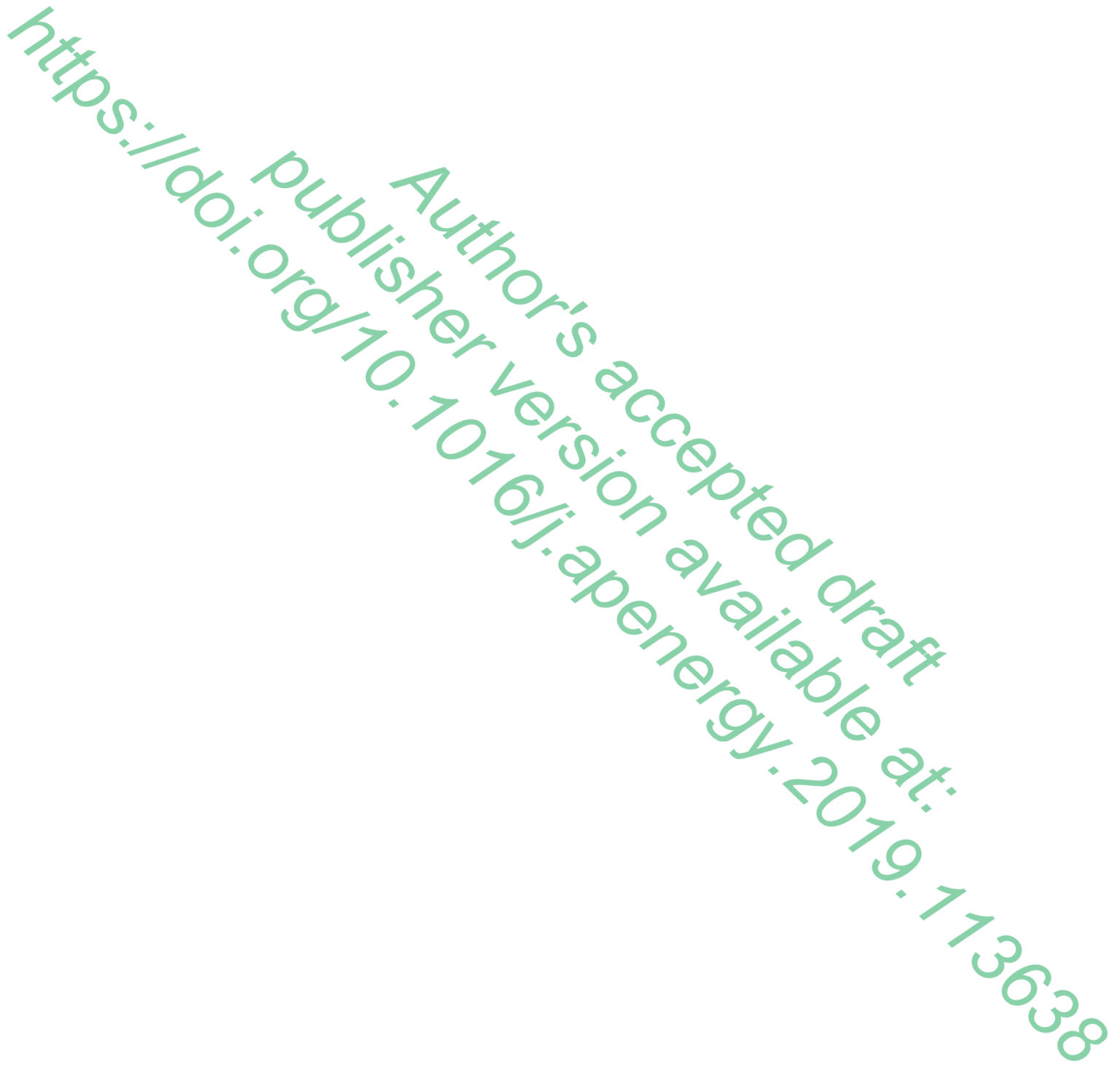




\section{APPENDICES}

Appendix A: XCCI Simulation model

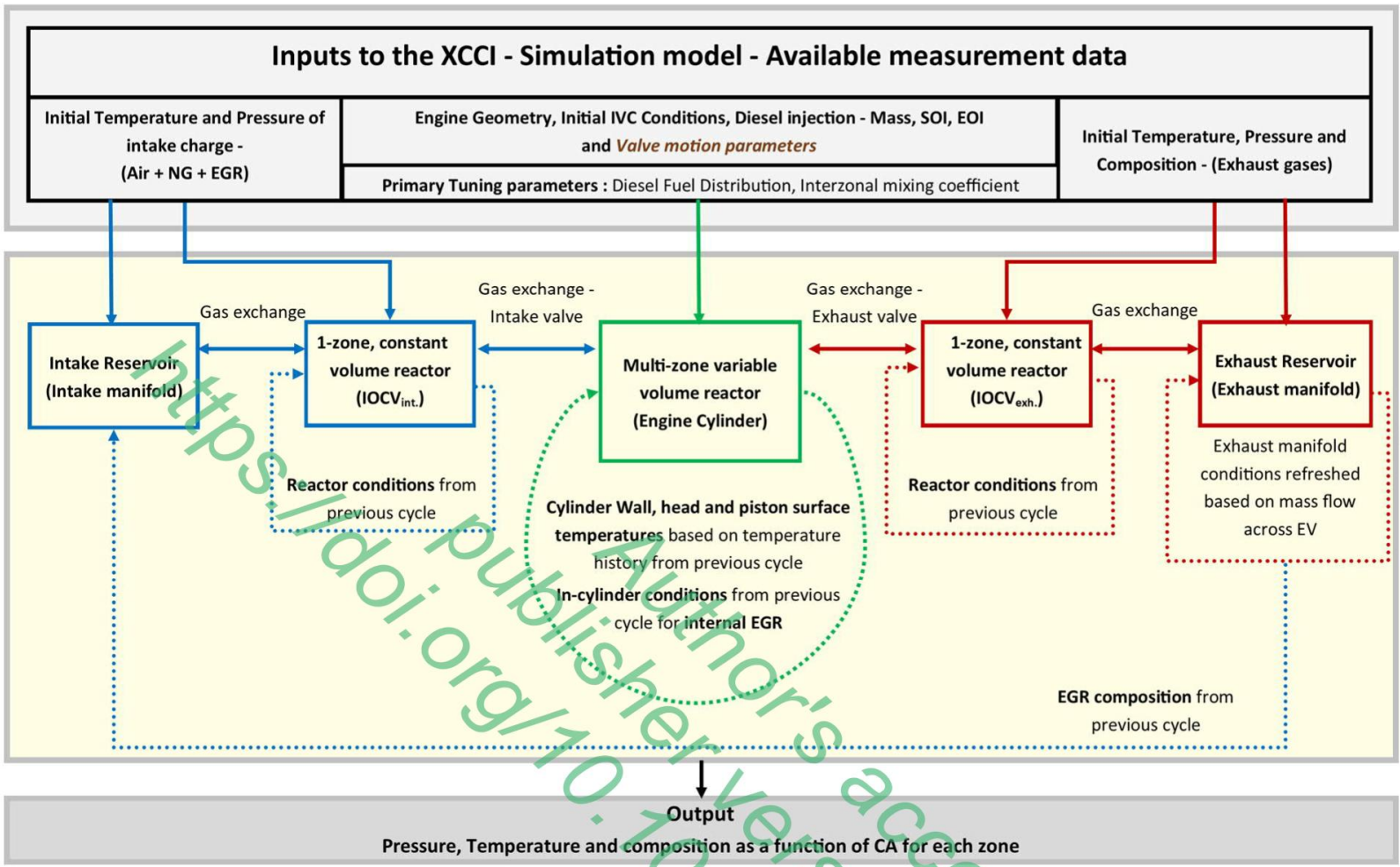

Model Initialization

Figure A 1: XCCl simulation model-detailed schematic.

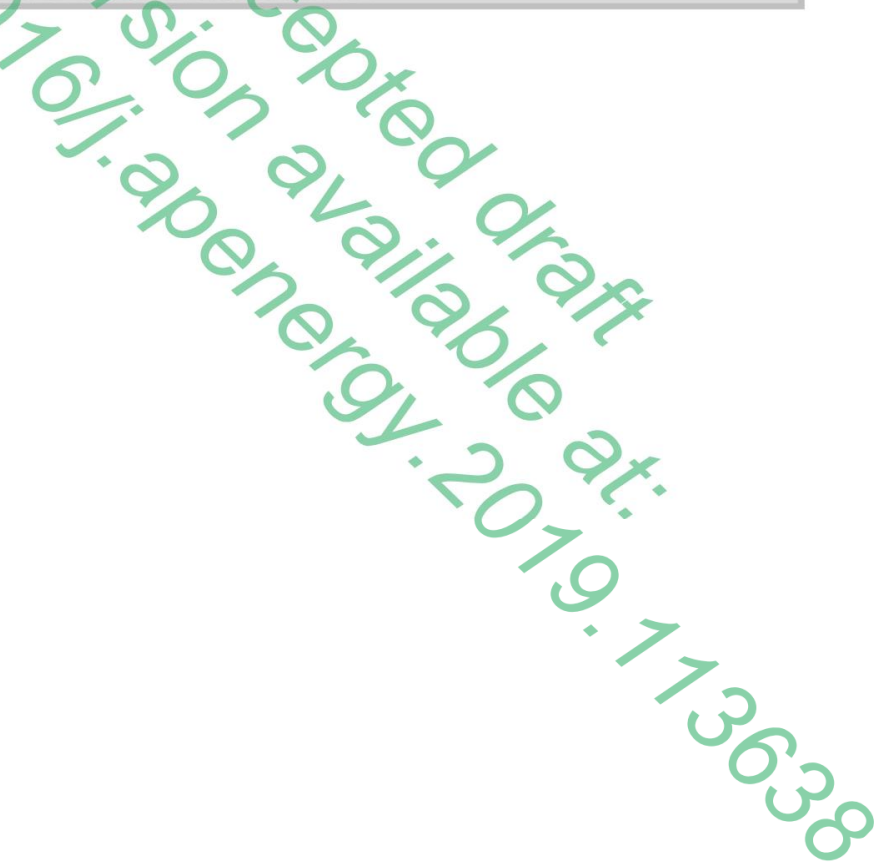


Appendix B: n-Heptane Ignition mechanism

Table B1. Mechanism for n-Heptane ignition: 30-step short mechanism model from Peters et al. [49]. High concentration of alkyl radicals observed during or end of NVO period and subsequently transferred to the main combustion phase follow the reaction pathways as mentioned in this table. A [mol-cm-s-K], $n[-]$ and $E[\mathrm{~kJ} / \mathrm{mol}]$ are Arrhenius reaction rate parameters: $k=$ $A T^{n} \cdot \exp (E / R T)$.

Number
1
2
3
4
5
6
7
$8 \mathrm{f}$
$8 \mathrm{~b}$
$9 \mathrm{f}$
$9 \mathrm{~b}$
$10 \mathrm{f}$
$10 \mathrm{~b}$
11
12
13
14
15
16
17
18
19
20
21
22
23
24
25
26
27
28
29
30

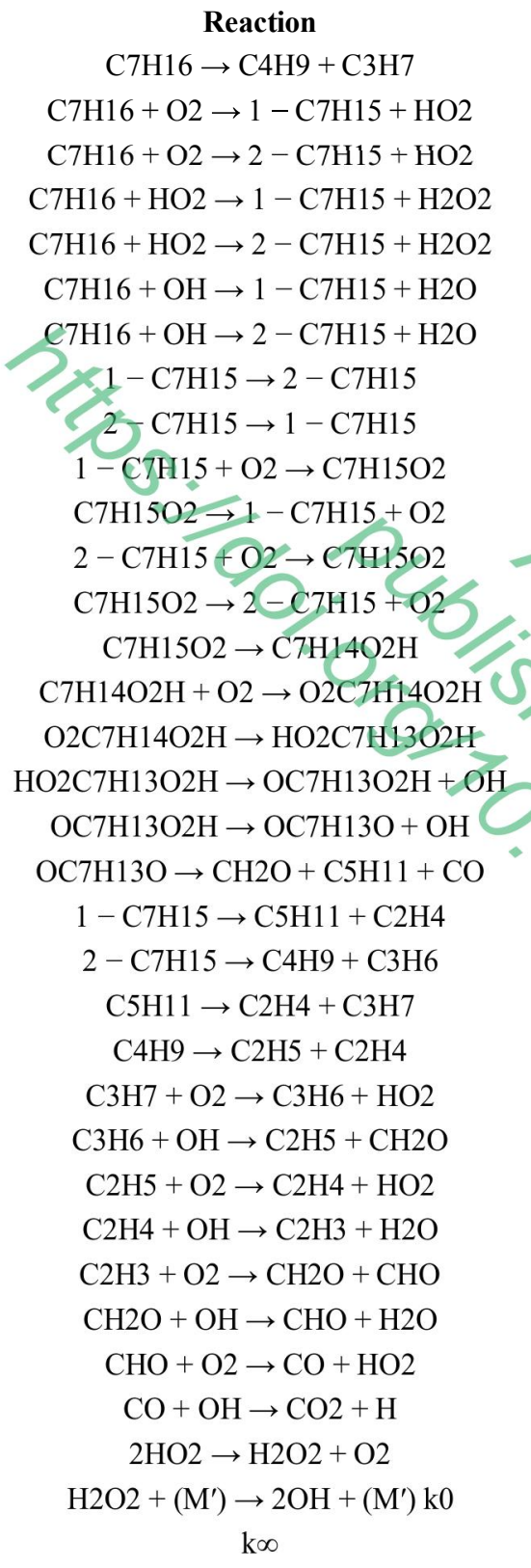

Reaction

$\mathrm{C} 7 \mathrm{H} 16 \rightarrow \mathrm{C} 4 \mathrm{H} 9+\mathrm{C} 3 \mathrm{H} 7$

$\mathrm{C} 7 \mathrm{H} 16+\mathrm{O} 2 \rightarrow 1-\mathrm{C} 7 \mathrm{H} 15+\mathrm{HO} 2$

$\mathrm{C} 7 \mathrm{H} 16+\mathrm{O} 2 \rightarrow 2-\mathrm{C} 7 \mathrm{H} 15+\mathrm{HO} 2$

$\mathrm{C} 7 \mathrm{H} 16+\mathrm{HO} 2 \rightarrow 1-\mathrm{C} 7 \mathrm{H} 15+\mathrm{H} 2 \mathrm{O} 2$

$\mathrm{C} 7 \mathrm{H} 16+\mathrm{HO} 2 \rightarrow 2-\mathrm{C} 7 \mathrm{H} 15+\mathrm{H} 2 \mathrm{O} 2$

$\mathrm{C} 7 \mathrm{H} 16+\mathrm{OH} \rightarrow 1-\mathrm{C} 7 \mathrm{H} 15+\mathrm{H} 2 \mathrm{O}$

$\mathrm{C} 7 \mathrm{H} 16+\mathrm{OH} \rightarrow 2-\mathrm{C} 7 \mathrm{H} 15+\mathrm{H} 2 \mathrm{O}$

$\times 1-\mathrm{C} 7 \mathrm{H} 15 \rightarrow 2-\mathrm{C} 7 \mathrm{H} 15$

$2-\mathrm{C} 7 \mathrm{H} 15 \rightarrow 1-\mathrm{C} 7 \mathrm{H} 15$

$1-\mathrm{C} 7 \mathrm{H} 15+\mathrm{O} 2 \rightarrow \mathrm{C} 7 \mathrm{H} 15 \mathrm{O} 2$

$\mathrm{C} 7 \mathrm{H} 15 \mathrm{O} 2 \rightarrow 1-\mathrm{C} 7 \mathrm{H} 15+\mathrm{O} 2$

$2-\mathrm{C} 7 \mathrm{H} 15+\mathrm{O} 2 \rightarrow \mathrm{C} 7 \mathrm{H} 15 \mathrm{O} 2$

$\mathrm{C} 7 \mathrm{H} 15 \mathrm{O} 2 \rightarrow 2-\mathrm{C} 7 \mathrm{H} 15+\mathrm{O} 2$

$\mathrm{C} 7 \mathrm{H} 15 \mathrm{O} 2 \rightarrow \mathrm{C} 7 \mathrm{H} 14 \mathrm{O} 2 \mathrm{H}$

$\mathrm{C} 7 \mathrm{H} 14 \mathrm{O} 2 \mathrm{H}+\mathrm{O} 2 \rightarrow \mathrm{O} 2 \mathrm{C} 7 \mathrm{H} 14 \mathrm{O} 2 \mathrm{H}$

$\mathrm{O} 2 \mathrm{C} 7 \mathrm{H} 14 \mathrm{O} 2 \mathrm{H} \rightarrow \mathrm{HO} 2 \mathrm{C} 7 \mathrm{H} 13 \mathrm{O} 2 \mathrm{H}$

$\mathrm{HO} 2 \mathrm{C} 7 \mathrm{H} 13 \mathrm{O} 2 \mathrm{H} \rightarrow \mathrm{OC} 7 \mathrm{H} 13 \mathrm{O} 2 \mathrm{H}+\overparen{\mathrm{OH}}$

$\mathrm{OC} 7 \mathrm{H} 13 \mathrm{O} 2 \mathrm{H} \rightarrow \mathrm{OC} 7 \mathrm{H} 13 \mathrm{O}+\mathrm{OH}$

$\mathrm{OC} 7 \mathrm{H} 13 \mathrm{O} \rightarrow \mathrm{CH} 2 \mathrm{O}+\mathrm{C} 5 \mathrm{H} 11+\mathrm{CO}$

$$
\begin{gathered}
1-\mathrm{C} 7 \mathrm{H} 15 \rightarrow \mathrm{C} 5 \mathrm{H} 11+\mathrm{C} 2 \mathrm{H} 4 \\
2-\mathrm{C} 7 \mathrm{H} 15 \rightarrow \mathrm{C} 4 \mathrm{H} 9+\mathrm{C} 3 \mathrm{H} 6 \\
\mathrm{C} 5 \mathrm{H} 11 \rightarrow \mathrm{C} 2 \mathrm{H} 4+\mathrm{C} 3 \mathrm{H} 7 \\
\mathrm{C} 4 \mathrm{H} 9 \rightarrow \mathrm{C} 2 \mathrm{H} 5+\mathrm{C} 2 \mathrm{H} 4
\end{gathered}
$$$$
\mathrm{C} 3 \mathrm{H} 7+\mathrm{O} 2 \rightarrow \mathrm{C} 3 \mathrm{H} 6+\mathrm{HO} 2
$$$$
\mathrm{C} 3 \mathrm{H} 6+\mathrm{OH} \rightarrow \mathrm{C} 2 \mathrm{H} 5+\mathrm{CH} 2 \mathrm{O}
$$$$
\mathrm{C} 2 \mathrm{H} 5+\mathrm{O} 2 \rightarrow \mathrm{C} 2 \mathrm{H} 4+\mathrm{HO} 2
$$$$
\mathrm{C} 2 \mathrm{H} 4+\mathrm{OH} \rightarrow \mathrm{C} 2 \mathrm{H} 3+\mathrm{H} 2 \mathrm{O}
$$$$
\mathrm{C} 2 \mathrm{H} 3+\mathrm{O} 2 \rightarrow \mathrm{CH} 2 \mathrm{O}+\mathrm{CHO}
$$$$
\mathrm{CH} 2 \mathrm{O}+\mathrm{OH} \rightarrow \mathrm{CHO}+\mathrm{H} 2 \mathrm{O}
$$$$
\mathrm{CHO}+\mathrm{O} 2 \rightarrow \mathrm{CO}+\mathrm{HO} 2
$$$$
\mathrm{CO}+\mathrm{OH} \rightarrow \mathrm{CO} 2+\mathrm{H}
$$$$
2 \mathrm{HO} 2 \rightarrow \mathrm{H} 2 \mathrm{O} 2+\mathrm{O} 2
$$$$
\mathrm{H} 2 \mathrm{O} 2+\left(\mathrm{M}^{\prime}\right) \rightarrow 2 \mathrm{OH}+\left(\mathrm{M}^{\prime}\right) \mathrm{k} 0
$$$$
\mathrm{k} \infty
$$

$\begin{array}{ccc}\mathbf{A} & \mathbf{n} & \mathbf{E} \\ 3.160 \mathrm{E}+16 & 0.00 & 339 \\ 6.000 \mathrm{E}+13 & 0.00 & 221 \\ 4.000 \mathrm{E}+13 & 0.00 & 210 \\ 5.000 \mathrm{E}+13 & 0.00 & 85.5 \\ 3.360 \mathrm{E}+13 & 0.00 & 74 \\ 1.050 \mathrm{E}+10 & 0.97 & 6.65 \\ 9.400 \mathrm{E}+07 & 1.61 & -0.146 \\ 2.000 \mathrm{E}+11 & 0.00 & 75.8 \\ 2.000 \mathrm{E}+11 & 0.00 & 75.8 \\ 2.500 \mathrm{E}+12 & 0.00 & 0 \\ 2.200 \mathrm{E}+15 & 0.00 & 117 \\ 2.500 \mathrm{E}+12 & 0.00 & 0 \\ 2.200 \mathrm{E}+15 & 0.00 & 117 \\ 2.000 \mathrm{E}+11 & 0.00 & 71.2 \\ 5.600 \mathrm{E}+12 & 0.00 & 0 \\ 2.000 \mathrm{E}+11 & 0.00 & 71.2 \\ 1.000 \mathrm{E}+09 & 0.00 & 31.4 \\ 8.400 \mathrm{E}+14 & 0.00 & 180 \\ 2.000 \mathrm{E}+13 & 0.00 & 62.8 \\ 2.500 \mathrm{E}+13 & 0.00 & -121 \\ 1.200 \mathrm{E}+13 & 0.00 & 018 \\ 7.972 \mathrm{E}+17 & -1.44 & 125 \\ 2.500 \mathrm{E}+13 & 0.00 & 121 \\ 1.000 \mathrm{E}+12 & 0.00 & 20.9 \\ 7.900 \mathrm{E}+12 & 0.00 & 0 \\ 1.024 \mathrm{e}+10 & 0.00 & -9.15 \\ 2.048 \mathrm{E}+13 & 0.00 & 24.9 \\ 1.700 \mathrm{E}+29 & -5.31 & 27.2 \\ 3.433 \mathrm{E}+09 & 1.18 & -1.9 \\ 3.011 \mathrm{E}+12 & 0.00 & 0 \\ 4.400 \mathrm{E}+06 & 1.50 & -3.1 \\ 1.867 \mathrm{E}+12 & 0.00 & 6.44 \\ 1.200 \mathrm{E}+17 & 0.00 & 190.4 \\ 3.000 \mathrm{E}+14 & 0.00 & 202.9\end{array}$

E

$$
10
$$$$
5.5
$$$$
65
$$

5.8$$
0
$$$$
0
$$$$
117
$$$$
1.2
$$$$
.4
$$

$$
0
$$
0.4 02.9
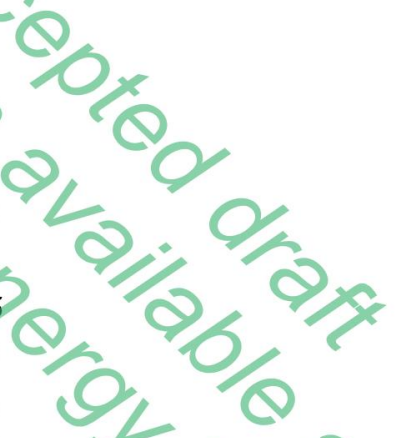

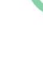

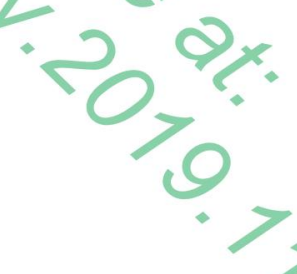

